Revista Brasileira de Cartografia

ISSN 1808-0936 | https://doi.org/10.14393/revbrascartogr

Sociedade Brasileira de Cartografia, Geodésia, Fotogrametria e Sensoriamento Remoto

\title{
Mapeamento da Vegetação do Cerrado - Uma Revisão das Iniciativas de Sensoriamento Remoto
}

\author{
Mapping the Cerrado's Vegetation Cover - A Review of Remote Sensing Initiatives
}

Marceli Terra de Oliveira ${ }^{1}$, Henrique Luis Godinho Cassol ${ }^{2}$, Khalil Ali Ganem ${ }^{3}$, Andeise Cerqueira Dutra ${ }^{4}$, Juan Doblas Prieto ${ }^{5}$, Egidio Arai ${ }^{6}$ e Yosio Edemir Shimabukuro ${ }^{7}$

1 Instituto Nacional de Pesquisas Espaciais (INPE), Divisão de Observação da Terra e Geoinformática (DIOTG), São José dos Campos, SP, Brasil. marceliterra@gmail.com.

ORCID: https://orcid.org/0000-0001-6087-6344

2 Instituto Nacional de Pesquisas Espaciais (INPE), Divisão de Observação da Terra e Geoinformática (DIOTG), São José dos

Campos, SP, Brasil. hlcassol@hotmail.com.

ORCID: https://orcid.org/0000-0001-6728-4712

3 Instituto Nacional de Pesquisas Espaciais (INPE), Divisão de Observação da Terra e Geoinformática (DIOTG), São José dos

Campos, SP, Brasil. khalilganem@ hotmail.com.

ORCID: https://orcid.org/0000-0001-9126-7138

4 Instituto Nacional de Pesquisas Espaciais (INPE), Divisão de Observação da Terra e Geoinformática (DIOTG), São José dos

Campos, SP, Brasil. andeise.dutra@inpe.br.

ORCID: https://orcid.org/0000-0002-4454-7732

5 Instituto Nacional de Pesquisas Espaciais (INPE), Divisão de Observação da Terra e Geoinformática (DIOTG), São José dos

Campos, SP, Brasil. juan.doblas@inpe.br.

ORCID: https://orcid.org/0000-0002-2573-3783

6 Instituto Nacional de Pesquisas Espaciais (INPE), Divisão de Observação da Terra e Geoinformática (DIOTG), São José dos

Campos, SP, Brasil. egidio.arai@inpe.br.

ORCID: https://orcid.org/0000-0003-1994-5277

7 Instituto Nacional de Pesquisas Espaciais (INPE), Divisão de Observação da Terra e Geoinformática (DIOTG), São José dos

Campos, SP, Brasil. yosio.shimabukuro@inpe.br.

ORCID: https://orcid.org/0000-0002-1469-8433

Recebido: 08.2020 | Aceito: 11.2020

Resumo: O Cerrado é o segundo maior bioma brasileiro, sendo reconhecido como a savana mais biodiversa do mundo. Após 1970, as dinâmicas de uso e cobertura da terra do bioma têm sido marcadas por atividades agropecuárias extensivas, resultando em taxas de desmatamento historicamente superiores às do bioma Amazônia. Esse cenário reforça a necessidade de investigar a metodologia das iniciativas de mapeamento da vegetação do Cerrado, a fim de identificar as lacunas e desafios ainda existentes para o avanço científico do conhecimento no âmbito do Sensoriamento Remoto (SR). Para tal, o presente artigo de revisão identificou 15 iniciativas que mapearam a vegetação do bioma em diferentes escalas, períodos e níveis de detalhamento de legenda. $\mathrm{O}$ primeiro foi o projeto Radam/RadamBrasil, ainda na década de 1970. No entanto, foi a partir dos anos 2000 que o Cerrado começou a ter mais visibilidade, com o surgimento de iniciativas maiores e mais direcionadas para o bioma (PROBIO, Conservação Internacional). Recentemente, novas iniciativas (MapBiomas, PRODES) têm se destacado por incorporarem metodologias diferenciadas que acompanharam a evolução computacional das técnicas de Sensoriamento Remoto. O levantamento realizado neste artigo identificou que a discriminação dos diferentes tipos de cobertura vegetal do bioma ainda é um dos principais desafios a serem vencidos, principalmente em relação às fitofisionomias não florestais, além de classes de uso espectralmente semelhantes, como a pastagem. Este trabalho visa agregar detalhes das principais iniciativas de mapeamento da vegetação do Cerrado, suas metodologias, desafios encontrados, tais como a dificuldade de discriminação de seus tipos de vegetação e maiores discussões e promessas futuras no campo do SR.

Palavras-chave: Savana. Fitofisionomia. Sensores orbitais.

Abstract: The Cerrado is the second largest Brazilian biome, being recognized as the most biodiverse savanna in the world. Beginning in 1970, the land use and land cover dynamics in the biome have been characterized by extensive agricultural activities, resulting in historically higher deforestation rates than the Amazon biome. This scenario reinforces the need to investigate the methodology initiatives of the Cerrado's vegetation cover, aiming to identify the gaps and challenges that still exist for the advancement of scientific knowledge in the Remote Sensing (RS) field. To 
this end, this review article identified 15 initiatives that mapped the biome's vegetation at different scales, periods, and legend levels. The first was the Radam/RadamBrasil project, in the 1970s. However, it was not until the 2000s that Cerrado began to have more visibility, with the emergence of larger and more targeted initiatives for the biome (PROBIO, Conservation International). Recently, new initiatives (MapBiomas, PRODES) have stood out for incorporating different methodologies that have followed the computational evolution of the Remote Sensing techniques. The research carried out in this article identified that the discrimination of different land cover types in the biome is still one of the main challenges to be overcome, especially regarding the non-forest phytophysiognomies as well as the land-use classes that are spectrally similar, such as pasture. This study aims to aggregate details of the main initiatives for mapping the Cerrado vegetation, as well as their methodologies, challenges encountered, such as the difficulty in discriminating its vegetation types, and further discussions and future prospects in the field of RS.

Keywords: Savanna. Phytophysiognomy. Orbital Sensors.

\section{INTRODUÇÃO}

O bioma Cerrado é um dos hotspots para a conservação da biodiversidade mundial (MYERS et al., 2000) e é reconhecida como a savana mais rica em termos de biodiversidade, abrangendo mais de 10.000 espécies vegetais e apresentando índices de endemismos superiores a 44\% (SIMON et al., 2009). O bioma se destaca como o segundo maior do Brasil, ocupando cerca de $22 \%$ da área total do país, estendendo-se por mais de dois milhões de $\mathrm{km}^{2}$ (MMA, 2020a). Também é uma reserva significativa de carbono, com estoque estimado em aproximadamente 8,73Gt de carbono orgânico, presente na biomassa e no compartimento do solo (REIS et al., 2017). De um total de 12 regiões hidrológicas presentes no Brasil, oito estão situadas no Cerrado, incluindo a segunda maior reserva subterrânea de água doce mundial, o Aquífero Guarani (REIS et al., 2017).

Apesar da importância e risco associado, o bioma apresenta 8,21\% de seu território legalmente protegido, sendo que desse percentual, apenas 2,85\% se refere a Unidades de Conservação de Proteção Integral. Dentre todos os hotspots mundiais, o Cerrado é o que possui a menor proporção de áreas protegidas integralmente (MMA, 2020a). O histórico de transformações ocorridas no Cerrado contribuiu para o surgimento de danos ambientais de grande impacto, tais como fragmentação de hábitat, extinção da biodiversidade, invasão de espécies exóticas, erosão de solos, poluição de aquíferos, degradação de ecossistemas, alteração nos regimes de queimadas e desequilíbrios no ciclo do carbono.

Após 1970, a ocupação no bioma se intensificou, principalmente, devido à produção de grãos como soja, milho e feijão, muito embora as pastagens cultivadas sejam uma das suas principais classes de uso e ocupação (SANO et al., 2010). As taxas de desmatamento no Cerrado têm sido historicamente superiores às da floresta Amazônica devido ao menor esforço governamental em prol da sua conservação (KLINK; MACHADO, 2005; SANO et al., 2019b). Machado et al. (2004) estimaram taxas de desmatamento de 1,5\% e 0,67\% ao ano nos períodos de 1985-1993 e 1993-2002, respectivamente, períodos estes que se relacionam ao aumento da criação de gado e, posteriormente, à intensificação do plantio de soja. Já para o período de 20022013, o TerraClass Cerrado aponta que o bioma perdeu sua vegetação natural em uma taxa de 0,41\% ao ano, muito maior que a taxa de 0,29\% da Amazônia Legal para o mesmo período (SANO et al., 2019b). Projeções para 2050 indicam que o Cerrado pode perder até 34\% de sua vegetação nativa, levando à extinção de pelo menos mil espécies endêmicas, o que corresponderia a um impacto oito vezes superior ao de extinção mundial de plantas desde o ano de 1500 (STRASSBURG et al., 2017).

As evidências da formação do Cerrado, as condições climáticas, geológicas, edáficas, bem como de manejo ao longo dos anos criaram condições fitogeográficas que permitiram uma alta heterogeneidade das formações florestais, savânicas e campestres presentes no bioma. Sob uma perspectiva fisionômica, as florestas se caracterizam pela predominância de espécies arbóreas, onde há formação de dossel, contínuo ou descontínuo. Já o termo savana se refere a arbustos e árvores espalhados por um estrato gramíneo, sem formação de dossel contínuo. Por fim, os campos são áreas com predominância de herbáceas e algumas espécies arbustivas, com ausência de árvores na paisagem (RIBEIRO; WALTER, 1998; WALTER, 2006; GIROLAMO NETO, 2018). Estas formações foram divididas em quatorze fitofisionomias de acordo com o manual técnico da vegetação brasileira e, por isso, demandam técnicas de manejo e níveis de exploração/preservação diferenciados em cada uma delas.

Para entender as transformações ocorridas no bioma e o futuro dos remanescentes vegetais naturais é 
preciso voltar no tempo e analisar as iniciativas de mapeamento da vegetação, as lacunas entre elas e a evolução da discussão ambiental sobre o bioma. Nesse sentido, o Sensoriamento Remoto surge como uma poderosa ferramenta para o mapeamento da vegetação e da dinâmica temporal da supressão versus a expansão agropecuária no bioma. Um grande desafio neste contexto é o mapeamento das diversas fisionomias dada a gradativa descaracterização destes ambientes ocasionada pela degradação e antropização, resultando em um aumento da confusão espectral entre classes. Por exemplo, o Cerrado perdeu $106.427 \mathrm{~km}^{2}$ de área entre $2002-$ 2011, com uma perda média de $\sim 0,7 \%$ da área do bioma ao ano (MMA, 2015a). Se continuar nesse ritmo de perda, o desafio de realizar o monitoramento e o mapeamento da vegetação aumentará no futuro juntamente com a necessidade de controle e fiscalização da expansão agropecuária no Cerrado.

Dentre estas iniciativas, a grande maioria utiliza sensores ópticos de média a moderada resolução espacial (30-250 m). Pesquisas recentes apontam que sensores de alta resolução espacial são essenciais para discriminar níveis hierárquicos maiores na classificação das múltiplas fisionomias vegetais (GIROLAMO NETO; FONSECA; KÖRTING, 2017; NEVES et al., 2020). Além disso, técnicas orientadas a objetos como GEOBIA têm-se mostrado úteis para realizar a segmentação de pixels em regiões homogêneas antes de realizar a classificação propriamente dita, sem desconsiderar que esta técnica reduz o erro de classificação em um ambiente heterogeneamente complexo (NEVES et al., 2020). Classificadores de aprendizado profundo de máquina - técnica conhecida com Deep Learning, serão o futuro do reconhecimento de padrões na imagem, pois permitem que informações contextuais sejam envolvidas na análise, alcançando exatidões muitas vezes superiores a $90 \%$ na classificação. O avanço da computação em nuvem e de forma sinérgica com múltiplos dados/sensores (ópticos, radares, LiDAR, climatológicos, etc.) também abre caminho para novas técnicas e métodos de processamento de imagens em múltiplas escalas, permitindo uma melhor compreensão e avaliação das classes e suas transições.

Neste contexto, este estudo visa agregar detalhes das principais iniciativas de mapeamento da vegetação do Cerrado, suas metodologias, desafios encontrados, tais como a dificuldade de discriminação de seus tipos de vegetação e maiores discussões e promessas futuras no âmbito do Sensoriamento Remoto. Assim, o presente trabalho está dividido em três partes: na primeira parte trazemos a definição do Cerrado e suas principais subdivisões (fitofisionomias), que são úteis para nortear as iniciativas de mapeamento do bioma. $\mathrm{Na}$ segunda parte, apresentamos as principais inciativas regionais e continentais de mapeamento da vegetação do Cerrado, com dados públicos disponibilizados para a comunidade. Por fim, na terceira parte, estabelecemos as diretrizes e perspectivas futuras de mapeamento do Cerrado, sejam elas nos níveis locais ou regionais para aumentar a exatidão da classificação, bem como, para contemplar níveis hierárquicos mais detalhados das principais fisionomias.

\section{O CERRADO}

O bioma Cerrado está presente nos estados de Goiás (GO), Tocantins (TO), Mato Grosso (MT), Mato Grosso do Sul (MS), Minas Gerais (MG), Bahia (BA), Maranhão (MA), Piauí (PI), Rondônia (RO), Paraná (PR), São Paulo (SP) e Distrito Federal (DF) (Figura 1). 


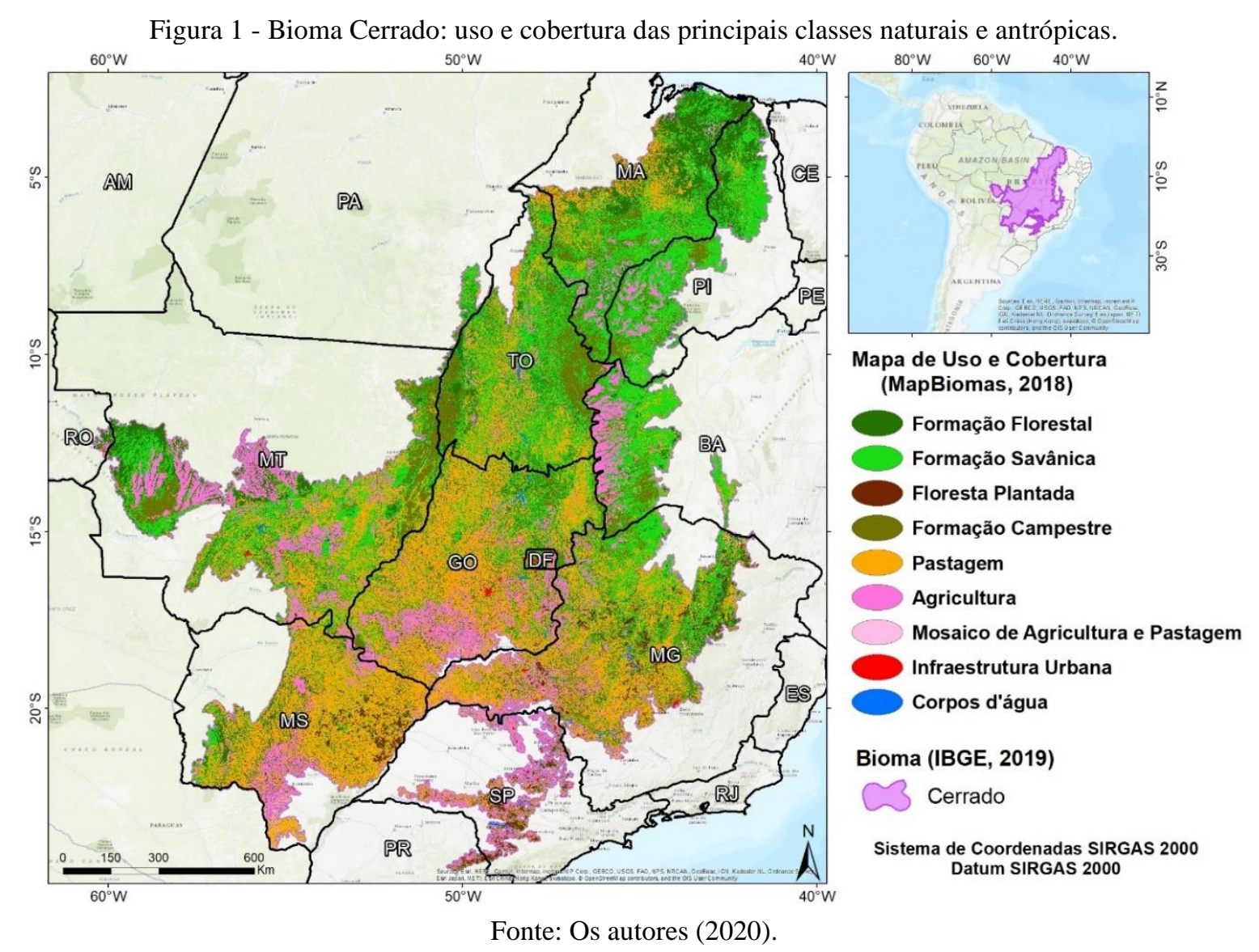

O clima do Cerrado caracteriza-se como estacional, com alternância entre inverno frio e seco (de abril a setembro) e verão quente e chuvoso (de outubro a março), sendo que no período de inverno a umidade relativa atinge níveis críticos (MIRANDA; SILVA; MIRANDA, 1996). A precipitação média anual é de $1.500 \mathrm{~mm}$ e as temperaturas são geralmente amenas ao longo do ano, variando entre $22^{\circ} \mathrm{C}$ e $27^{\circ} \mathrm{C}$, em média (KLINK; MACHADO, 2005). Devido às condições climáticas e à disponibilidade hídrica, a presença do fogo é constante na época seca, sendo considerado um fator determinante na modificação da paisagem do bioma (ARMANDO, 1994). O fogo é uma ferramenta de manejo antiga e amplamente utilizada no manuseio e na conservação das paisagens tropicais e, embora o Cerrado seja um ecossistema adaptado ao fogo natural, as queimadas utilizadas para estimular a rebrota das pastagens e expandir as fronteiras agrícolas causam problemas como perda da biodiversidade, alteração na estrutura dos ecossistemas, perda de nutrientes, entre outros (MISTRY; BIZERRIL, 2011).

A vegetação do Cerrado possui diversas fitofisionomias que, de acordo com Ribeiro e Walter (1998), são divididas em formações florestais (Mata Ciliar, Mata de Galeria, Mata Seca e Cerradão) (Figura 2), savânicas (Cerrado sentido restrito, Parque de Cerrado, Palmeiral e Vereda) e campestres (Campo Sujo, Campo Rupestre e Campo Limpo) (Figura 3). Os critérios adotados para a diferenciação dessas áreas são baseados, primeiramente, na forma, a qual é definida pela estrutura, modos de crescimento dominantes e por possíveis mudanças estacionais. Posteriormente, são considerados fatores edáficos e de composição florística. No caso de fitofisionomias caracterizadas por subtipos, o ambiente e a composição florística foram os critérios de diferenciação utilizados pelos autores. Essas formações têm origem, classificações e fitofisionomias distintas.

As formações florestais do Cerrado são resultado de alterações substanciais do clima e da geomorfologia, que levaram à expansão e retração das florestas da Amazônia e da Mata Atlântica, bem como das florestas semidecíduas da Caatinga. Em períodos glaciais quaternários, tipicamente secos, florestas secas e formações vegetais abertas se expandiram, atingindo áreas que hoje pertencem ao Cerrado (RIBEIRO; WALTER, 1998). Evidências dessa natureza caracterizam-se pela distribuição geográfica de muitas espécies nativas dessas florestas em diferentes biomas ou áreas disjuntas que englobam o Cerrado (BIGARELLA; ANDRADE-LIMA; RIEHS, 1975). Ao mesmo tempo, sob uma perspectiva espacial, formações como estas seriam influenciadas por variações locais na hidrografia, topografia, profundidade dos solos e do aquífero. 
Figura 2 - Fotos de campo referentes às áreas dos Parques Nacionais de Brasília (DF) e Chapada dos Veadeiros (GO). a)
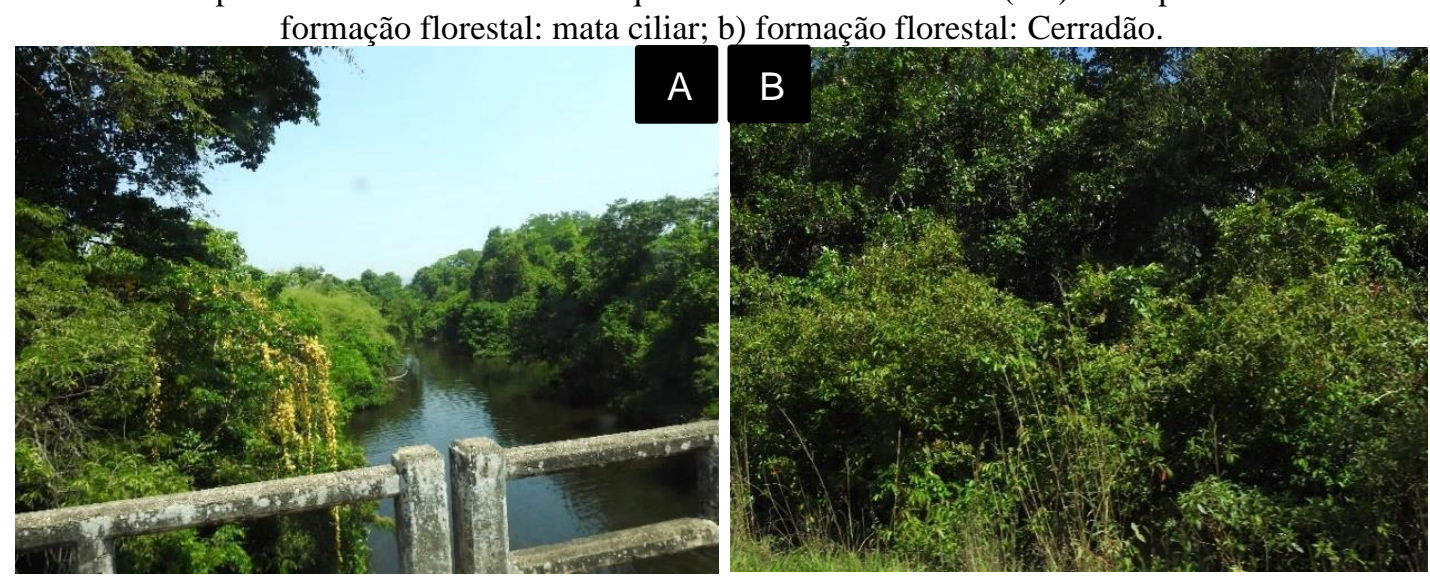

Fonte: Os autores (2020).

A origem das formações savânicas e campestres, por sua vez, é bastante discutida na literatura inerente ao tema (BEARD, 1953; ALVIM, 1954; EITEN, 1972; COUTINHO, 1978; GOODLAND; FERRI, 1979). De acordo com Eiten (1994), as formas fisionômicas do Cerrado dependeriam da fertilidade, da profundidade do solo e do seu grau de saturação hídrica. As precipitações, em escala evolutiva, intemperizaram os solos, reduzindo o teor de nutrientes essenciais e aumentando a disponibilidade de alumínio. Com isso, pode-se dizer que a vegetação foi definida como resultado indireto do clima. Ribeiro e Walter (1998) sintetizaram as diversas teorias existentes para explicar o surgimento dessas formações em três grupos, utilizando termos sugeridos por Beard (1953): 1 - a vegetação seria resultado do clima, principalmente devido à limitação sazonal de água no período de estiagem (teorias climáticas); 2 - a vegetação seria o resultado de ação antrópica, principalmente devido ao uso frequente do fogo; ou ainda resultante da atividade de outros agentes da biota, como as formigas (teorias bióticas); e 3 - a vegetação seria dependente de aspectos edáficos e geológicos, como ausência de minerais, excesso de alumínio, diferença de drenagem e profundidade dos solos (teorias pedológicas).

Figura 3 - Fotos de campo referentes às áreas dos Parques Nacionais de Brasília (DF) e Chapada dos Veadeiros (GO). a) formação savânica: cerrado sentido restrito; b) formação campestre: campo sujo e, ao horizonte, campo limpo.
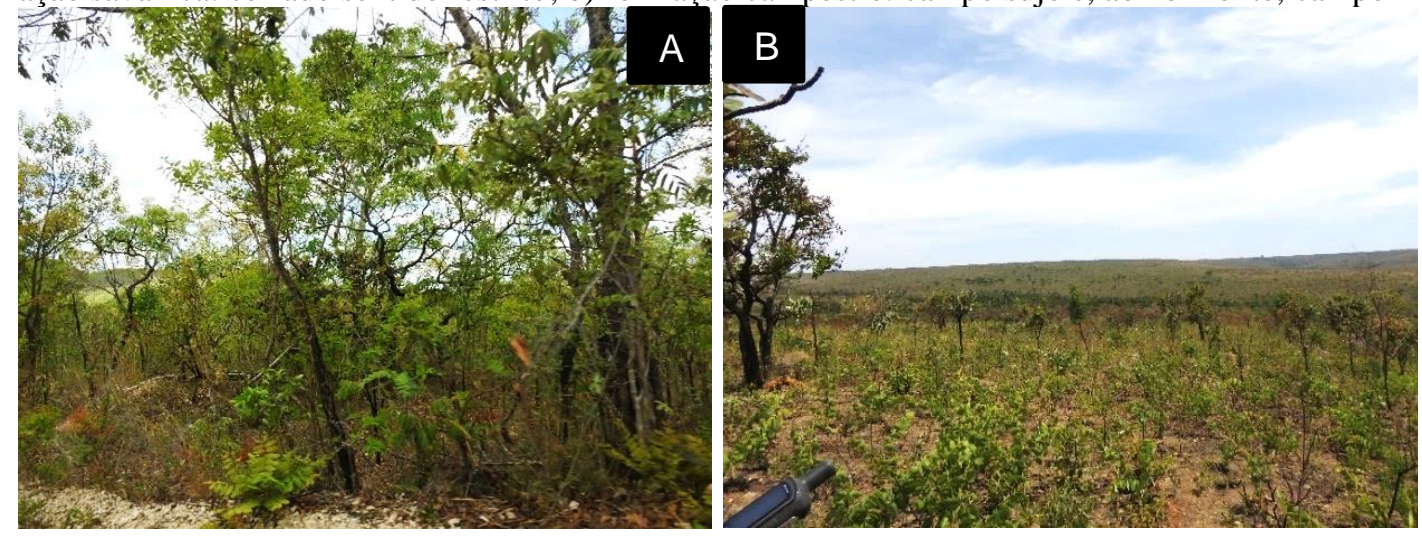

Fonte: Os autores (2020).

A principal causa da supressão vegetal do Cerrado é a expansão agropecuária, principalmente em função da produção de carne e grãos no Brasil. O controle do desmatamento na Amazônia, intensificado a partir de 2004 com o Plano de Ação para Prevenção e Controle do Desmatamento na Amazônia Legal (PPCDAm), mudou esta fronteira agrícola para locais onde há menor rigidez em termos de cumprimento da lei, como é o caso do Cerrado, onde a supressão da vegetação é permitida por lei em até $65 \%$ da área, diferente dos 20\% na Amazônia (BRASIL, 2012). Em 2006, foi implementada a moratória da soja na Amazônia, com o compromisso da não comercialização da produção de grãos provenientes de áreas desmatadas após a implementação do acordo (GIBBS et al., 2015; FARIA, 2018). Posteriormente, em 2008, foi criada a lista de municípios prioritários na Amazônia Legal como medida restritiva, em que municípios participantes sofreriam sanções. O Cerrado, que na época era amparado apenas pelo código florestal vigente, começou a ser explorado 
em seus remanescentes naturais, principalmente na região do MATOPIBA (Maranhão, Tocantins, Piauí e Bahia). Essa região, que além de possuir os maiores remanescentes do bioma, possui um valor sobre a terra muito inferior ao de regiões já consolidadas (FARIA, 2018).

O MATOPIBA é considerado atualmente como a nova fronteira agrícola do país, pois possui topografia plana, solos profundos e o clima favorável ao cultivo das principais culturas de grãos e fibras. A região do MATOPIBA reúne 337 municípios e representa cerca de 73 milhões de hectares, sendo que destes, $61,20 \%$ é composto por cobertura savânica que, por sua vez, apresenta o maior número de espécies endêmicas (WALTER, 2006). Existem ainda na região 324 mil estabelecimentos agrícolas, 46 unidades de conservação, 35 terras indígenas e 781 assentamentos de reforma agrária, segundo levantamento feito pelo Grupo de Inteligência Estratégica (GITE) da Embrapa (EMBRAPA, 2019). Esse cenário reforça a importância de se combater o desmatamento no bioma, principalmente em áreas estratégicas, evitando a fragmentação da vegetação e o aumento de manchas isoladas.

\section{INICIATIVAS DE MAPEAMENTO DA VEGETAÇÃO}

No âmbito do Sensoriamento Remoto, o Projeto Radam (1970) é considerado o primeiro mapeamento nacional para o conhecimento e apropriação dos recursos naturais do país. Seu objetivo foi efetuar o levantamento dos recursos naturais em uma porção da Amazônia, por meio de Sensoriamento Remoto por radar (SLAR - radar de visada lateral) (IBGE, 2018). Após o sucesso do mapeamento, o mesmo foi expandido para todo o território nacional e renomeado RadamBrasil (1975). Ambos os projetos utilizaram o avião Sud SE.210 Caravelle (IBGE, 2018), voando com altitude média de $12 \mathrm{~km}$ e velocidade média de $690 \mathrm{~km} / \mathrm{h}$. O sistema sensor acoplado à aeronave foi o GEMS (Goodyear Mapping System 1000), operando na banda X (comprimentos de onda próximos a $3 \mathrm{~cm}$ e frequência entre 8 e 12,5 GHz) (ESCOBAR et al., 2005).

Assim, por 10 anos e contando com cerca de 700 profissionais, o projeto produziu 38 volumes da "Série Levantamento de Recursos Naturais", os quais continham relatórios e mapas temáticos nas escalas 1:1.000.000 e cartas-imagem em 1:250.000 com levantamento de dados geológicos, geomorfológicos, pedológicos, uso potencial da terra e vegetação (IBGE, 2018). Em termos de vegetação, algumas cartasimagem abrangem a vegetação do Cerrado, tais como as cartas Goiás, Goiânia, Brasília, entre outras. Além do sistema GEMS, esse mapeamento também utilizou imagens do sensor MSS/Landsat 2, interpretação visual e uma série de visitas em campo para analisar a vegetação a nível fisionômico. Todo esse material está disponível na biblioteca online do IBGE (IBGE, 2020).

A partir de 1982, a serviço do Projeto RadamBrasil, Góes Filho e Veloso (1982) propuseram um novo sistema fisionômico-ecológico da classificação da vegetação brasileira (Figura 4), acrescido de uma legenda para mapeamento em escala regional. Esse trabalho também serviu como base para a classificação da vegetação brasileira (VELOSO; RANGEL FILHO; LIMA, 1991) e para a elaboração do manual técnico da vegetação brasileira (IBGE, 1992), ambos do Instituto Brasileiro de Geografia e Estatística (IBGE) e os quais sofreram atualizações ao longo dos anos. Por fim, o projeto RadamBrasil ampliou o foco para o campo das geociências no Brasil, impulsionando pesquisas variadas que passaram a destacar o potencial do Sensoriamento Remoto em estudos ambientais. 


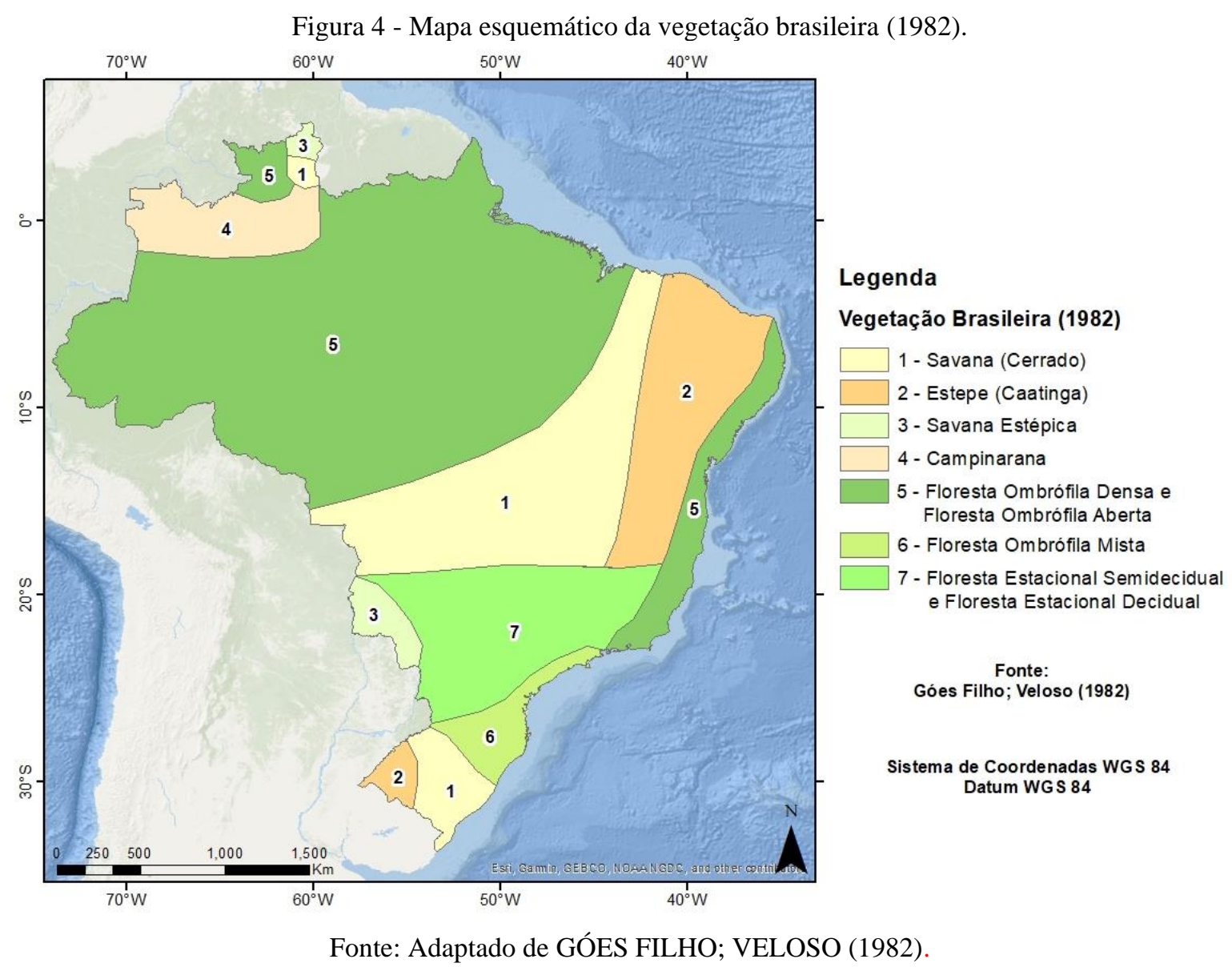

Apesar da trajetória bem-sucedida, o RadamBrasil foi descontinuado em 1985, fazendo com que novas iniciativas precisassem surgir para preencher a lacuna de dados, principalmente nos anos finais da década de 1980. Assim surgiu o PRODES (1988), motivado por dois trabalhos prévios que demonstraram as potencialidades do uso de dados orbitais do sistema Landsat para avaliar o impacto da implantação de projetos agropecuários da Amazônia (TARDIN; SANTOS; NOVO, 1977) e para o levantamento de áreas de desmatamento na Amazônia Legal (TARDIN et al., 1979). Porém, o PRODES era limitado apenas à região amazônica, abrangendo uma parcela pouco significativa de fitofisionomias savânicas do Cerrado restritas à Amazônia Legal e em zonas de transição.

A estimativa de conversão da vegetação remanescente no Cerrado entre 1970-2000 é imprecisa, justamente devido à dependência dos dados do RadamBrasil como base para estudos posteriores (FARIA, 2018). No entanto, o mapeamento do bioma começou a ganhar maior visibilidade a partir dos anos 2000, quando o Ministério do Meio Ambiente (MMA) divulgou dois editais para a seleção de subprojetos de mapeamento da cobertura vegetal por meio do Projeto de Conservação e Utilização Sustentável da Diversidade Biológica Brasileira, o PROBIO (2004). Os subprojetos do PROBIO utilizaram como base imagens ETM+/Landsat 7 de 2002 compreendendo todos os biomas em uma escala de 1:250.000 (MMA, 2009). Para o Cerrado, o estudo foi uma cooperação entre a Embrapa Cerrados, Universidade Federal de Uberlândia (UFU) e o Instituto de Estudos Socioambientais da Universidade Federal de Goiás (IESA/UFG), e esses dados encontram-se disponíveis no website do MMA (MMA, 2020). 
Figura 5 - Imagens ETM+/Landsat 7 de reflectância de superfície de 2001-2003, em composição R5G4B3 e filtradas para menos de 30\% de nuvens, ilustrativas à iniciativa do PROBIO (2004). Os limites em roxo centrais referem-se aos limites do bioma Cerrado e em preto as grades ( $\mathrm{grid}$ ) das cenas Landsat.

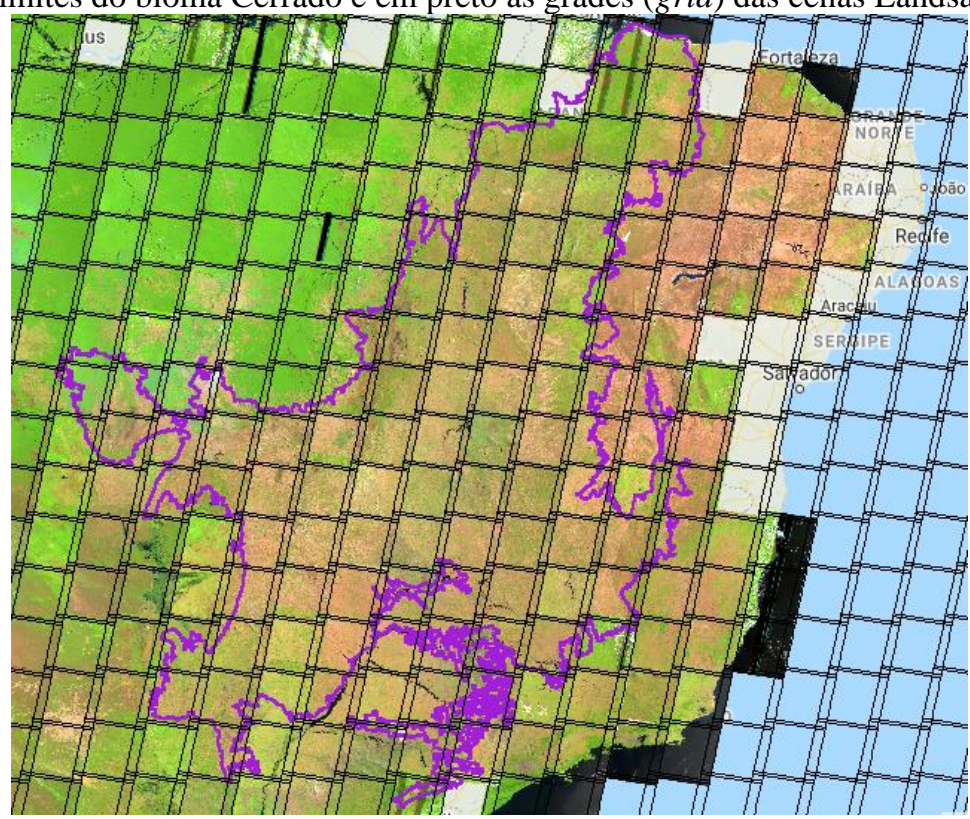

Fonte: Os autores (2020).

No âmbito do PROBIO, o bioma foi analisado, em sua maioria, a partir de um mosaico de 114 cenas ETM+/Landsat 7 (ilustração na Figura 5) correspondentes ao período de agosto a outubro, coincidindo com a estação seca e com uma menor cobertura de nuvens (MMA, 2007). A metodologia do projeto difere de outras iniciativas ao utilizar técnicas de segmentação de imagens, reduzindo o tempo de interpretação visual. Ao considerar 2002 como ano base do estudo, os resultados obtidos pelo PROBIO indicaram que a vegetação nativa representava $60,42 \%$ do bioma, porém, esse percentual considera aproximadamente 28 milhões de hectares de pastagens (computadas pelo Censo Agropecuário do IBGE 1995/1996) na categoria de vegetação nativa. Ao considerar esse valor como antrópico, a vegetação nativa remanescente foi reduzida para 46,74\% (SANO et al., 2007). Ainda, os resultados apontam (Tabela 1) que a maior parte da vegetação remanescente do bioma em 2002 era composta por fisionomias de formações savânicas (36,73\%), enquanto na área antropizada as pastagens cultivadas (26,45\%) recobriam uma maior parcela do bioma (MMA, 2007). É importante destacar que esses resultados são referentes dos limites antigos do bioma, proposto pelo IBGE, o qual teve atualização em 2019. Dessa forma, a comparação do percentual dos resultados do PROBIO com resultados atuais pode não ser compatível.

Tabela 1 - Valor da área ocupada por cobertura vegetal natural em cada unidade federativa coberta pelo Cerrado. *A parcela de Cerrado no estado de Rondônia não foi discriminada nos resultados por ser muito pequena, portanto, a parcela foi incluída no estado do Mato Grosso (MT).

\begin{tabular}{l|c|c|c|c|c}
\hline UF* & $\begin{array}{c}\text { \% do bioma na } \\
\text { UF }\end{array}$ & $\begin{array}{c}\text { Formação Florestal } \\
\text { (ha) }\end{array}$ & $\begin{array}{c}\text { Formação Savânica } \\
\text { (ha) }\end{array}$ & $\begin{array}{c}\text { Formação Campestre } \\
\text { (ha) }\end{array}$ & $\begin{array}{c}\text { Vegetação Natural } \\
(\boldsymbol{\%})\end{array}$ \\
\hline SP & 33 & 833.387 & 210.441 & 34.888 & $\mathbf{1 3}$ \\
PR & 2 & 20.558 & 14.048 & 84.085 & $\mathbf{3 2}$ \\
MS & 61 & 2.867 .267 & 3.599 .826 & 468.311 & $\mathbf{3 2}$ \\
DF & 100 & 44.645 & 162.718 & 6.164 & $\mathbf{3 7}$ \\
GO & 97 & 2.929 .033 & 11.090 .161 & 687.502 & $\mathbf{4 4}$ \\
MG & 57 & 3.279 .762 & 11.322 .147 & 3.192 .964 & $\mathbf{5 3}$ \\
MT & 40 & 7.717 .102 & 15.868 .080 & 155.151 & $\mathbf{6 6}$ \\
BA & 27 & 3.333 .902 & 7.357 .605 & 518.389 & $\mathbf{7 4}$ \\
TO & 92 & 4.639 .932 & 13.362 .688 & 2.249 .165 & $\mathbf{7 9}$ \\
MA & 65 & 12.337 .965 & 6.032 .951 & 382.790 & $\mathbf{8 9}$ \\
PI & 37 & 2.319 .035 & 6.210 .085 & 61.462 & $\mathbf{9 1}$ \\
\hline
\end{tabular}

Fonte: Adaptado de MMA (2007).

A exatidão global e índice Kappa para os resultados do mapeamento do PROBIO foram 74,19\% e $68,31 \%$, respectivamente. As maiores confusões foram observadas entre as classes de pastagens cultivadas e as classes de culturas agrícolas e reflorestamento, o que pode ser explicado pela maior similaridade espectral 
entre ambas. De acordo com os autores, a confusão intra-classe também pode ser explicada pela prática de rotação de culturas em uma mesma área, além de reflorestamentos que se encontram em estágios iniciais. Ao agrupar as classes em um nível de legenda mais abrangente (cobertura natural, antrópica e massa de água), os índices aumentaram para 96,5\% e 92,3\%.

A organização brasileira Conservação Internacional (2004) (MACHADO et al., 2004) realizou um mapeamento do Cerrado utilizando o produto MOD43b4 (na época, relativo ao NBAR - Nadir BRDF-Adjusted Reflectance) do sensor MODIS. Esse dado foi escolhido devido a sua maior estabilidade e consistência, e por ser um produto ajustado para a remoção dos efeitos angulares. Assim, a iniciativa utilizou 9 cenas referentes ao ano de 2002 (ilustração na Figura 6), as quais foram classificadas pelo método supervisionado por máxima verossimilhança (MaxVer) e validadas por interpretação visual a partir de cenas ETM+/Landsat 7. O resultado indicou que 54,9\% do Cerrado correspondia a áreas nativas desmatadas no referido ano (MACHADO et al., 2004).

No entanto, os próprios autores alegaram que os resultados foram superestimados devido a resolução espacial $(1 \mathrm{~km})$ do dado utilizado aliada à ausência de visitas em campo para validar os dados. Mesmo assim, a iniciativa representou uma grande contribuição para estudos voltados para a quantificação da vegetação do Cerrado por esclarecer que, apesar dos remanescentes estarem associados a extensas áreas em termos numéricos, essas parcelas encontravam-se em grande parte sob áreas de terrenos desfavoráveis à implantação de grandes projetos agrícolas ou com falta de infraestrutura básica. Machado et al. (2004) ainda estimaram taxas de desmatamento de $1,5 \%$ e $0,67 \%$ ao ano (aproximadamente $30.000 \mathrm{~km}^{2}$ e $22.000 \mathrm{~km}^{2}$ ao ano) nos períodos de 1985-1993 e 1993-2002, respectivamente, períodos estes que se relacionam ao aumento da criação de gado e, posteriormente, à intensificação do plantio de soja. Por fim, os autores estimaram que o Cerrado desapareceria em 2030, caso as taxas de desmatamento fossem mantidas na mesma frequência e intensidade.

Figura 6 - Imagens MODIS NBAR de agosto/2002, composição R6G2B1, ilustrativas à iniciativa de Machado et al. (2004). Os limites em roxo referem-se aos limites do bioma Cerrado e em preto as grades (tiles) das cenas MODIS.

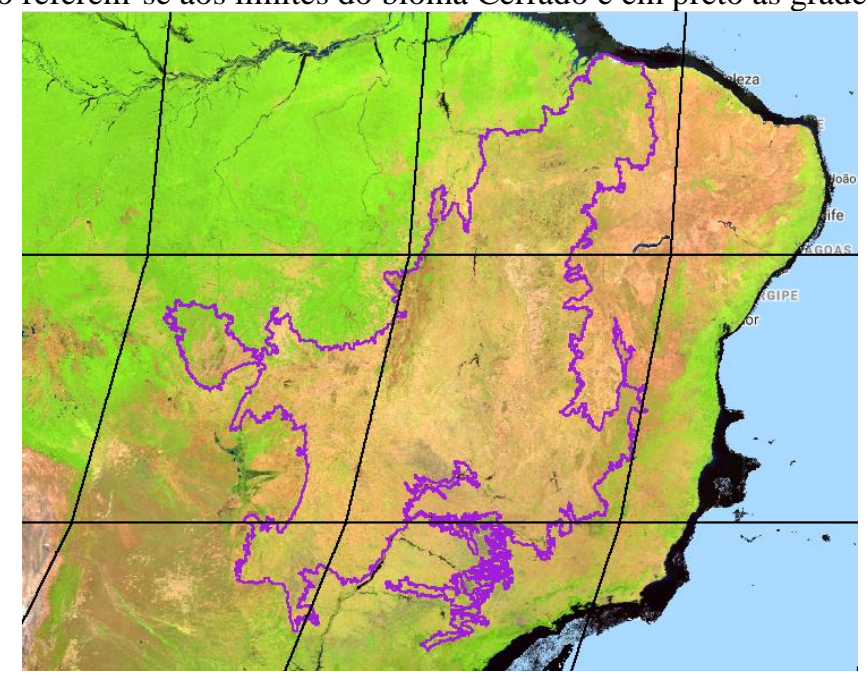

Fonte: Os autores (2020).

Ainda em 2004, Eva et al. (2004) produziram um mapa de cobertura do solo da América do Sul, com imagens de 1995-2000 dos programas ATSR-2 (Along Track Scanning Radiometer), SPOT VGT e DMSP OLS (Defense Meteorological Satellite Program - Operational Linescan System), todas com resolução espacial de $1 \mathrm{~km}$. O Cerrado é representado no mapeamento pelas classes campos, savanas e agricultura. No entanto, por se tratar de um mapa de maior abrangência geográfica, o nível de detalhamento das classes de vegetação é por si só mais generalista.

As lacunas referentes ao mapeamento do Cerrado nos anos seguintes foram parcialmente preenchidas por algumas iniciativas estaduais, tais como São Paulo (2005) e Minas Gerais (2006). O Instituto Florestal do governo do estado de São Paulo realizou a caracterização espacial e a quantificação dos remanescentes naturais e dos reflorestamentos com espécies exóticas (Pinus e Eucalyptus) no estado. Para isso, a iniciativa fez uso de imagens CBERS-2 do período 2000-2001, bem como fotointerpretação com imagens TM/Landsat 5, ETM+/Landsat 7 e fotografias aéreas. Ao final, 3,5 milhões de hectares (14\% do estado) de área foram 
mapeadas, dentre as quais 210.000 hectares correspondem à fitofisionomias do Cerrado (0,85\% do estado) (KRONKA et al., 2005; SANO et al., 2007). No ano seguinte, Scolforo e Carvalho (2006) publicaram um livro por meio da Universidade de Lavras sobre o mapeamento e inventário da flora nativa e dos reflorestamentos do estado de Minas Gerais. Os autores utilizaram imagens TM/Landsat 5 e ETM+/Landsat 7 de 2003 (primavera, verão e inverno), dados de campo, transformação Tasseled Cap e classificação por árvores de decisão. Os resultados tiveram exatidão de $90.8 \%$ para um nível de legenda específico das fitofisionomias do Cerrado (CARVALHO, 2005).

Em 2008, o MMA, juntamente com o Instituto Brasileiro do Meio Ambiente e dos Recursos Naturais Renováveis (IBAMA) e o Programa das Nações Unidas para o Desenvolvimento (PNUD), deu início ao Projeto de Monitoramento do Desmatamento dos Biomas Brasileiros por Satélite (PMDBBS). O PMDBBS (2008) tinha como meta principal o combate aos desmatamentos ilegais nos biomas não-amazônicos (Cerrado, Caatinga, Mata Atlântica, Pampa e Pantanal), tendo como base os levantamentos realizados pelo PROBIO, porém em escala mais refinada, de 1:50.000 (MMA, 2009). Para isso, o projeto quantificou desmatamentos em áreas de vegetação nativa para subsidiar a definição de ações prioritárias de fiscalização (MAURANO; ALMEIDA; MEIRA, 2019). Os dados podem ser acessados no site do MMA (MMA, 2020).

Os mapeamentos das áreas desmatadas do Cerrado pelo PMDBBS utilizaram imagens TM/Landsat 5 e CBERS2B no período de 2002-2011, com polígonos de área mínima de dois hectares, interpretados por detecção visual e digitalização manual das áreas de remanescentes de vegetação do PROBIO. Os polígonos com detecção de desmatamento foram considerados como áreas antropizadas, não havendo outras classes identificadas. Além do período analisado (2002-2011), o projeto também revisou os polígonos apresentados pelo PROBIO (desmatamentos ocorridos até 2002), o que resultou na retificação da área desmatada do bioma de 38,98\% para 43,67\% (MMA, 2009). Esse percentual foi aumentado para 48,89\% em $2011 \mathrm{em}$ termos de área total desmatada, com exatidão de $88 \%$ (Tabela 2), quando a iniciativa foi descontinuada. O projeto ainda apontou uma taxa de desmatamento anual para o período de 2002-2008 de 0,69\% no Cerrado, a maior observada em comparação com outros biomas brasileiros (Pantanal: 0,47\%, Amazônia: 0,42\%, Caatinga: 0,33\% e Pampa: 0,20\%) (MMA, 2009).

Tabela 2 - Área total desmatada do Cerrado por período, de 2002 a 2011.

\begin{tabular}{cccccccc}
\hline & \multicolumn{4}{c}{ Área desmatada $\left(\mathbf{k m}^{2}\right)$} & \multicolumn{4}{c}{ Área desmatada total } \\
\hline Bioma $\left(\mathbf{k m}^{2}\right)$ & Anterior a 2002 & $2002-2008$ & $2008-2009$ & $2009-2010$ & $2010-2011$ & $\mathrm{~km}^{2}$ & $\%$ \\
\hline $\mathbf{2 . 0 3 9 . 3 8 6}$ & 890.636 & 85.074 & 7.637 & 6.469 & 7.247 & 997.063 & $\mathbf{4 8 , 8 9}$ \\
\hline
\end{tabular}

Fonte: Adaptado de MMA (2015b).

O MMA, juntamente com o LAPIG (Laboratório de Processamento de Imagens e Geoprocessamento) e as ONGs The Nature Conservancy e Conservação Internacional, deram início à iniciativa SIAD (Sistema de Alertas de Desmatamento). O SIAD (2008) utilizou dados de índice de vegetação do MODIS para obtenção das mudanças na cobertura vegetal dos remanescentes do bioma no período 2002-2009 (MMA, 2009). Os dados obtidos foram disponibilizados para consulta pública na plataforma online interativa da iniciativa, e as publicações vinculadas ao projeto podem ser acessadas no site do LAPIG (LAPIG, 2020).

O projeto Mapeamento do Uso e Cobertura Vegetal do Cerrado - TerraClass Cerrado (2013) é resultado da união do MMA, IBAMA (Instituto Brasileiro do Meio Ambiente), INPE, EMBRAPA, UFG (Universidade Federal de Goiás) e UFU (Universidade Federal de Uberlândia), e seus resultados são disponibilizados no site do INPE (INPE, 2020). A iniciativa forneceu resultados mais robustos de uso e cobertura da terra no Cerrado, refinando as classes a partir do uso de 121 imagens OLI/Landsat 8 do ano de 2013 (MMA, 2015a). Após a segmentação, os segmentos foram exportados com o módulo de classificação do SPRING e cada classe foi definida individualmente com base em parâmetros específicos como, por exemplo, a utilização de máscaras agrícolas, índice de vegetação (NDVI), filtragens, entre outros (MMA, 2015a).

De acordo com os últimos resultados do TerraClass Cerrado (Tabela 3), o total de área mapeada no bioma foi de 2.039.243 km², sendo que $1.111 .090 \mathrm{~km}^{2}(\sim 54 \%)$ correspondem às categorias de vegetação natural (florestas, savanas e campos). A iniciativa obteve exatidão de 80,2\% em seu mapeamento, o que é considerado um valor alto e aceitável, especialmente diante do nível de detalhamento da legenda. Uma crítica a esse dado é em relação à confusão entre as classes. Por exemplo, a classe "Pastagens" refere-se apenas às pastagens 
cultivadas, desconsiderando pastagens nativas, onde também há uso da terra, mas a vegetação é natural. Essas, por sua vez, foram classificadas como área natural não florestal (SANO et al., 2019b). Ainda assim, a transformação de áreas de vegetação nativa em pastagens e agricultura é notória e diretamente proporcional, tanto é que a agropecuária se tornou o tipo de uso de maior ameaça para o Cerrado. O projeto mostrou, ainda, que no período de 2002-2013, a taxa de perda de vegetação natural no bioma foi de $0,41 \%$ ao ano, excedendo consideravelmente a taxa de 0,29\% da Amazônia Legal para o mesmo período (SANO et al., 2019b).

Tabela 3 - Resultados do TerraClass Cerrado (2013). A área mínima mapeável é de 6,25 hectares e compatível com escala cartográfica de 1:250.000.

\begin{tabular}{c|c|c}
\hline Classes & Área (km $\mathbf{~})$ & Área $\mathbf{( \% )}$ \\
\hline Natural & & \\
Natural Florestal & 418.789 & 20,54 \\
Natural Não Florestal (Savânico e Campestre) & 692.301 & 33,95 \\
Natural não vegetado (bancos de areia, afloramento) & 2.609 & 0,13 \\
Água & 15.056 & 0,74 \\
Antrópico & 174.006 & 8,53 \\
Agricultura anual & 64.512 & 3,16 \\
Agricultura perene & 247 & 0,01 \\
Mineração & 2.326 & 0,11 \\
Mosaico de ocupações & 600.832 & 29,46 \\
Pastagem & 30.525 & 1,50 \\
Silvicultura & 3.621 & 0,18 \\
Solo exposto & 8.797 & 0,43 \\
Urbano & 73 & 0,00 \\
Outros & 25.549 & 1,25 \\
Total & $\mathbf{2 . 0 3 9 . 2 4 3}$ & $\mathbf{1 0 0 \%}$ \\
\hline
\end{tabular}

Fonte: Adaptado de INPE (2019a).

Um dos trabalhos de maior relevância na literatura inerente ao tema é o Global Forest Change (2013), proposto por Hansen et al. (2013), o qual mapeou o ganho e perda de floresta global no período de 2000 a 2012. Apesar de se tratar de um esforço de mapeamento a nível global, os levantamentos foram realizados com imagens orbitais ETM+/Landsat 7 (30 m), o que permite uma visualização em média resolução para a escala proposta. O Brasil se destaca nesse estudo por apresentar taxas de desmatamento reduzidas para o referido período. Além disso, os autores também chamaram a atenção para o fato de o país ser o único que produz e mantém a transparência dos dados anuais de extensão florestal e mudanças de uso e cobertura da terra. $\mathrm{O}$ conjunto de dados globais desse projeto é dividido em cenas de 10x10 graus, consistindo em arquivos que incluem, dentre outros, dados de ganho e perda florestal com exatidão de 99,6\%. Os dados foram gerados por classificações automatizadas baseadas em algoritmos de árvore de decisão e encontram-se disponíveis na plataforma criada por Hansen et al. (2013).

Considerando que o Cerrado é proporcionalmente menos estudado em comparação com a Amazônia, e dada a negligência ainda maior na literatura científica em estudos voltados para o mapeamento da vegetação do bioma Caatinga, Beuchle et al. (2015) produziram dados consistentes sobre as mudanças de cobertura da terra de ambos os biomas entre 1990 e 2010. Ao usarem imagens TM/ETM+/Landsat e classificação orientada ao objeto, os autores concluíram que os remanescentes vegetais do Cerrado representavam menos da metade da área total do bioma em 2010, ou seja, 47\%.

Em 2015 surgiu o Projeto de Mapeamento em Alta Resolução dos Biomas Brasileiros, criado pela Fundação Brasileira para o Desenvolvimento Sustentável - FBDS (2015), uma entidade sem fins lucrativos cujos projetos possuem como um dos focos o desenvolvimento sustentável de áreas rurais. Esse enfoque impulsionou o surgimento do projeto de mapeamento dos biomas por imagens de satélite, o qual teve como objetivo principal a produção de dados primários de uso e cobertura do solo, hidrografia e Áreas de Preservação Permanente (APP). Um dos aspectos inovadores desse projeto foi a adoção de uma escala inédita (1:25.000), além do uso de dados do satélite RapidEye (5 metros) (FBDS, 2015). O mapeamento foi gerado tendo 2013 como ano base e utilizou as bandas do visível e infravermelho próximo de cada imagem, as quais foram classificadas por método supervisionado para então serem vetorizadas. A iniciativa obteve exatidão de $95 \%$, o 
que evidencia o potencial que as imagens de alta resolução possuem em auxiliar a discriminação entre as classes, apesar do nível de legenda mais restrito em comparação com outras iniciativas. Os dados desse mapeamento está disponível para os biomas Cerrado e Mata Atlântica, e podem ser acessados no website da FBDS (FBDS, 2015).

Ainda no mesmo ano, especialistas de diferentes áreas se reuniram em um seminário para discutir novas oportunidades de mapeamento do território nacional no âmbito do sensoriamento remoto, o que deu origem ao Projeto de Mapeamento Anual da Cobertura e Uso do Solo no Brasil - MapBiomas (2015). Essa iniciativa multi-institucional produz dados de 1985 até os dias atuais por meio da plataforma de processamento em nuvem Google Earth Engine (GEE), totalizando mais de 30 anos de mapeamento para os seis biomas brasileiros. A iniciativa utiliza imagens TM/Landsat 5, ETM+/Landsat 7 e OLI/Landsat 8 e uma série de métricas para cada bioma e temas transversais para então gerar um único mosaico para todo o país (MAPBIOMAS, 2020a).

Esse mosaico é salvo como uma coleção de dados (Asset) no GEE e as equipes dos biomas e temas transversais geram camadas de mapeamento utilizando o algoritmo de classificação Random Forest, de forma automática. Essas camadas são posteriormente integradas e um único mapa final é gerado (MAPBIOMAS, 2020a). Não é necessário entendimento de Javascript ou noções de programação para acessar os dados, pois além de uma plataforma interativa, o MapBiomas produziu uma ferramenta (toolkit) acompanhada de tutoriais para acesso aos dados em seu website (MAPBIOMAS, 2020). De acordo com a coleção 5.0 do MapBiomas (Figura 7), os remanescentes naturais das formações florestais, savânicas e campestres do bioma Cerrado contabilizam $27 \%, 57 \%$ e $16 \%$, respectivamente, de um total de $1.065 .283 \mathrm{~km}^{2}$ em 2018 , o que representa menos da metade da área total do bioma.

Figura 7 - Remanescentes vegetais naturais do bioma Cerrado em 2018 a partir dos dados da coleção 5.0 do
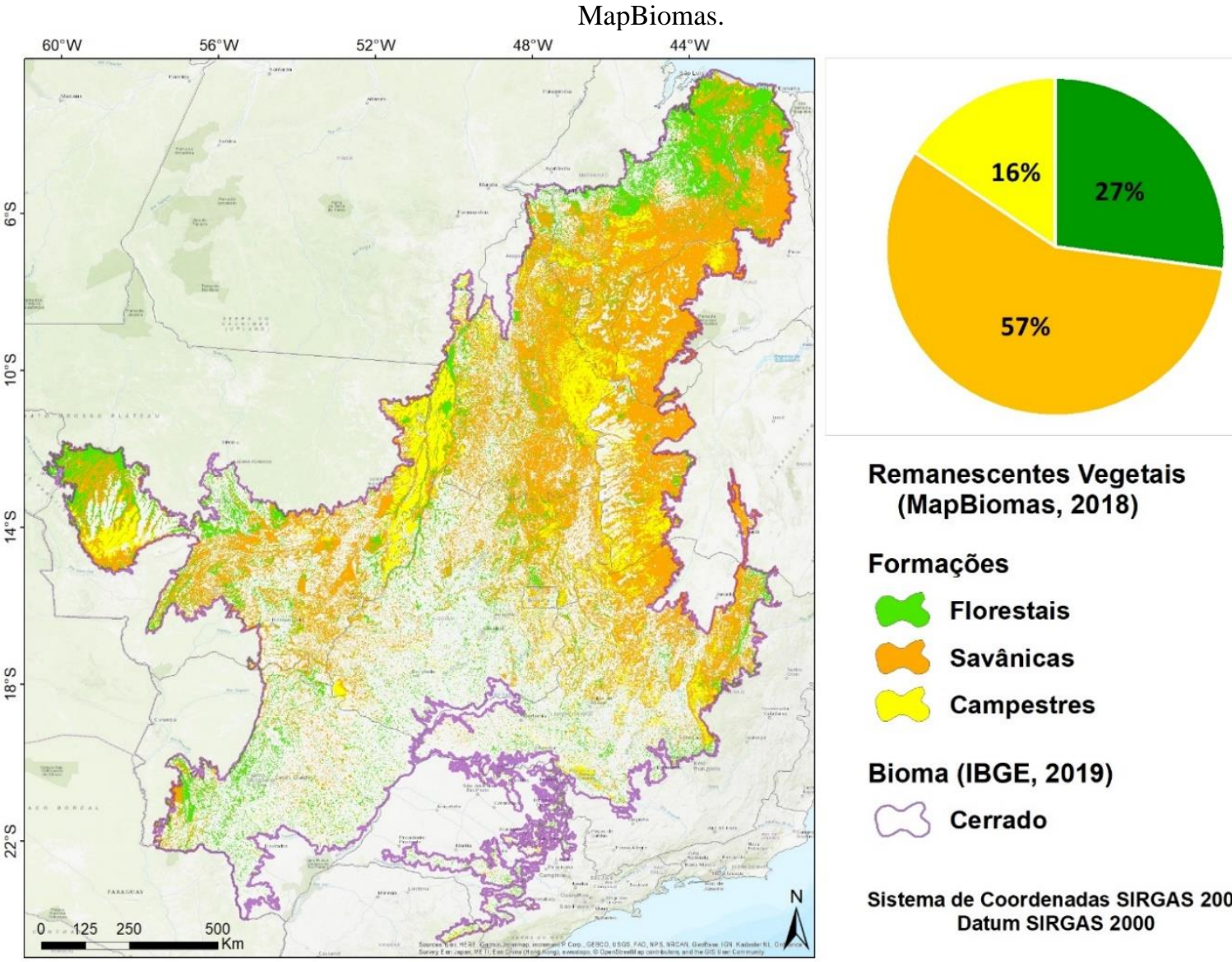

Remanescentes Vegetais

(MapBiomas, 2018)

\section{Formações}

Florestais

Savânicas

Campestres

\section{Bioma (IBGE, 2019)}

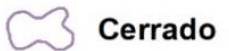

Sistema de Coordenadas SIRGAS 2000 Datum SIRGAS 2000

Fonte: Os autores (2020).

A acurácia global associada aos mapas do projeto MapBiomas tem evoluído de forma consistente ao longo do tempo, aumentando de $79 \%$ na coleção 2 para $91 \%$ na coleção 5, lançada em agosto de 2020 . Nesta coleção, as estatísticas fornecidas até o momento não consideraram o último ano (2019), e para o nível I de classificação, os mapas correspondentes ao bioma Cerrado oferecem exatidão de 83,8\%. A principal fonte de 
erro nas classificações fornecidas está vinculada à classe "Formação Natural não Florestal", que em 51\% das amostras avaliadas foi erroneamente classificada como "Agropecuária" ou "Floresta" (erro de inclusão). Igualmente, $45 \%$ das amostras classificadas como formações não florestais corresponderam, na amostra de validação, a outro tipo de cobertura (floresta ou agropecuária) (erro de omissão). Como era de se esperar, a exatidão correspondente ao nível II de classificação é menor. A exatidão global neste nível de classificação é de $81,6 \%$, sendo a maior confusão intra-classe relacionada à classe "Formação Campestre", que registra erro de inclusão e omissão de $51,5 \%$ e 44\%, respectivamente, para o ano 2018.

A exatidão correspondente ao bioma Cerrado é relativamente baixa, se comparada à exatidão global do bioma Amazônia (97,6\%) e à exatidão global de todos os biomas agrupados (91,2\%). Entende-se que isto é devido principalmente a dois fatores: 1) a já mencionada complexidade na discriminação dos tipos de vegetação natural não florestal do Cerrado e 2) a diferença nas metodologias usadas pelo projeto MapBiomas para a Amazônia e para o Cerrado. Com efeito, a equipe encarregada do bioma Amazônia usou, no algoritmo de classificação, a integralidade do conjunto de imagens Landsat incidentes sobre o bioma, de 1985 até 2018. Os outros biomas foram classificados usando uma única imagem representativa de cada ano, incorporando nela até 105 métricas correspondentes à série temporal anual, como o valor médio, máximo, mínimo de cada banda e de diversos índices e fracções espectrais. É de se esperar que a homogeneização do tratamento algorítmico dos diferentes biomas traga um expressivo ganho de exatidão nas classificações correspondentes ao bioma Cerrado nas próximas coleções do projeto MapBiomas.

A partir de 2016 o INPE desenvolveu o PRODES Cerrado (2016), por meio do Programa de Monitoramento Ambiental dos Biomas Brasileiros, dando início ao mapeamento do desmatamento ao longo de todo o bioma. O projeto produziu uma série histórica bienal no período de 2000-2012 e anual de 2013-2017 e, particularmente em 2016 e 2017, os dados produzidos são oriundos do projeto FIP FM Cerrado (MAURANO; ALMEIDA; MEIRA, 2019). Seguindo a metodologia do PRODES, as imagens utilizadas são provenientes da constelação Landsat (TM/Landsat 5 e OLI/Landsat 8), na escala cartográfica de 1:250.000 e com uma metodologia baseada em fotointerpretação, por meio do sistema TerraAmazon.

Primeiramente, o projeto selecionou imagens do ano 2000 para criar uma máscara dos desmatamentos já existentes. Para os anos subsequentes, foram identificados incrementos de desmatamento baseado em uma abordagem cumulativa, isto é, assegurando que os desmatamentos antigos não sejam mapeados novamente (MAURANO; ALMEIDA; MEIRA, 2019). A quantificação se dá em áreas com supressão maior do que um hectare e a ocorrência de desmatamento é considerada apenas quando há remoção completa da vegetação nativa. Essa abordagem garante a inclusão de todas as fitofisionomias do bioma e todos os dados podem ser acessados na plataforma Terra Brasilis (TERRABRASILIS, 2020). Ainda, conforme os dados do PRODES Cerrado, o desmatamento no bioma atingiu $283.200 \mathrm{~km}^{2}$ entre os anos $2001 \mathrm{e} \mathrm{2019}$, sendo que mais de 28.000 $\mathrm{km}^{2}$ equivale a áreas inferiores a 6,25 ha (INPE, 2020c). Nesse período, os estados mais desmatados foram Mato Grosso (46.054 km²), Goiás $\left(45.137 \mathrm{~km}^{2}\right)$ e Minas Gerais $\left(44.823 \mathrm{~km}^{2}\right)$.

Além dos mapeamentos voltados especificamente para a geração de dados de desmatamento e uso e cobertura da terra, o sistema DETER-B (2018) merece destaque por ter passado a englobar o bioma Cerrado nos avisos e alertas de desmatamento a partir de 2018 (INPE, 2020d). A iniciativa identifica e mapeia, quase em tempo real, desmatamentos e alterações na cobertura florestal com área mínima próxima a um hectare, utilizando imagens CBERS-4, IRS (Indian Remote Sensing) e interpretação visual, juntamente com a técnica de Modelo Linear de Mistura Espectral (MLME) (INPE, 2020e). Esses alertas são enviados diretamente ao IBAMA, que então prossegue com os protocolos de fiscalização dessas áreas. Esses dados encontram-se disponíveis na plataforma TerraBrasilis, juntamente com os dados do PRODES. A Tabela 4 apresenta um resumo das 15 iniciativas de mapeamento do Cerrado descritas nos parágrafos anteriores. 
Tabela 4 - Resumo das iniciativas de mapeamento da vegetação do Cerrado.

\begin{tabular}{|c|c|c|c|}
\hline Iniciativa & Objetivo & Sensor & Exatidão/Kappa \\
\hline 1975/RadamBrasil & $\begin{array}{c}\text { Relatórios e mapas temáticos nas escalas } \\
\text { 1:1.000.000 e cartas-imagem em 1:250.000 com } \\
\text { levantamento de dados geológicos, } \\
\text { geomorfológicos, pedológicos, uso potencial da } \\
\text { terra e vegetação }\end{array}$ & GEMS & 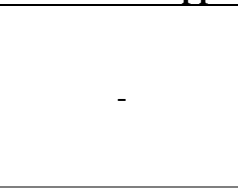 \\
\hline 2004/PROBIO & $\begin{array}{l}\text { Mapeamento da cobertura vegetal e uso da terra em } \\
1: 250.000 \text { de } 2002\end{array}$ & ETM+/Landsat-7 & $74,19 \% / 68,31 \%$ \\
\hline $\begin{array}{l}\text { 2004/Conservação } \\
\text { Internacional - } \\
\text { Machado et al. }\end{array}$ & Desmatamento no Cerrado de 2002 & MODIS & - \\
\hline 2004/Eva et al. & $\begin{array}{l}\text { Cobertura do solo da América do Sul de } 1995 \text { a } \\
2000\end{array}$ & $\begin{array}{c}\text { ATSR-2/SPOT } \\
\text { VGT/DMSP OLS }\end{array}$ & - \\
\hline Estaduais & $\begin{array}{c}\text { Remanescentes naturais e caracterização do } \\
\text { reflorestamento com espécies exóticas, 2000-2001 } \\
\text { (SP)/ Mapeamento e inventário da flora nativa e } \\
\text { dos reflorestamentos, } 2003 \text { (MG) }\end{array}$ & $\begin{array}{l}\text { CBERS-2/TM- } \\
\text { ETM+/Landsat-5-7 }\end{array}$ & $90,8 \% / 89,18 \%$ \\
\hline 2008/PMDBBS & $\begin{array}{c}\text { Quantificação de desmatamentos em áreas de } \\
\text { vegetação nativa em 1:50.000 }\end{array}$ & TM/Landsat-5 & $88-92 \%$ \\
\hline 2008/SIAD & $\begin{array}{l}\text { Mudanças na cobertura vegetal dos remanescentes } \\
\text { do bioma de 2002-2009 }\end{array}$ & MODIS & - \\
\hline $\begin{array}{l}\text { 2013/TerraClass } \\
\text { Cerrado }\end{array}$ & Uso e cobertura da terra do Cerrado de 2013 & OLI/Landsat-8 & $80,2 \%$ \\
\hline 2013/Hansen et al. & $\begin{array}{l}\text { Ganho e perda de floresta global no período de } \\
\qquad 2000 \text { a } 2012\end{array}$ & ETM+/Landsat-7 & $99,6 \%$ \\
\hline 2015/Beuchle et al. & $\begin{array}{c}\text { Mudanças de cobertura da terra nos biomas } \\
\text { Caatinga e Cerrado de } 1990 \text { a } 2010\end{array}$ & $\begin{array}{l}\text { TM-ETM+/Landsat-5- } \\
7\end{array}$ & - \\
\hline 2015/FBDS & $\begin{array}{l}\text { Produção de dados primários de uso e cobertura do } \\
\text { solo, hidrografia e Áreas de Preservação } \\
\text { Permanente (APP) do Cerrado e Mata Atlântica em } \\
1: 25.000 \text {, de } 2013\end{array}$ & RapidEye & $95 \%$ \\
\hline 2015/MapBiomas & $\begin{array}{l}\text { Mapeamento de uso e cobertura da terra de todo o } \\
\text { território nacional a partir de } 1985\end{array}$ & $\begin{array}{c}\text { TM-ETM+- } \\
\text { OLI/Landsat-5-7-8 }\end{array}$ & $70-95 \%$ \\
\hline $\begin{array}{l}\text { 2016/PRODES } \\
\text { Cerrado }\end{array}$ & Desmatamentos em 1:250.000 a partir de 2000 & TM-OLI/Landsat-5-8 & - \\
\hline 2018/DETER-B & $\begin{array}{l}\text { Desmatamentos e alterações na cobertura florestal } \\
\text { com área mínima próxima a } 1 \text { ha, a partir de } 2018\end{array}$ & CBERS-4/IRS & - \\
\hline
\end{tabular}

Fonte: Os autores (2020).

Uma análise preliminar das iniciativas apresentadas neste estudo permite identificar três categorias de mapeamento: desmatamento, uso e cobertura da terra e avisos/alertas. As iniciativas que mapeiam o desmatamento geralmente utilizam níveis de legenda mais simplificados, com enfoque na exatidão do produto final e no uso do método de fotointerpretação por especialistas e vetorização de polígonos baseado na abordagem do cálculo do desmatamento cumulativo. De forma semelhante funcionam os sistemas de avisos e alertas de desmatamento, cujo objetivo é auxiliar órgãos fiscalizadores e atender a demanda urgente de se lançar dados em tempo quase real. Por fim, os mapeamentos de uso e cobertura da terra, e avisos/alertas investem em técnicas de processamento de imagens, aplicação de algoritmos de classificação, bem como na otimização dos processos e apresentação dos dados por meio de abordagens automatizadas.

\section{DIRETRIZES E PERSPECTIVAS FUTURAS PARA O MAPEAMENTO DO CERRADO}

Há um consenso na literatura que o mapeamento da vegetação do Cerrado se dá com dados de Sensoriamento Remoto no nível hierárquico mais elevado (nível I), no qual o bioma é separado em três grandes classes, formações florestais, savânicas e campestres, e apresenta exatidão de classificação superior a $90 \%$ (SANO et al., 2010; NEVES et al., 2020). O desafio, entretanto, reside na discriminação destas classes em subcategorias, que contabilizam 11 fitofisionomias no nível II, ou até mesmo 25, no nível III, segundo "As Principais Fitofisionomias do Bioma Cerrado" de Ribeiro e Walter (2008).

Portanto, aqui apresentamos algumas diretrizes e perspectivas futuras que visam aprimorar o mapeamento do Cerrado em níveis mais detalhados, como os níveis II e III. Pesquisas recentes apontam para a subdivisão do Cerrado em ecorregiões com o intuito de agregar áreas homogêneas com relação às 
características edafoclimáticas, geomorfológicas e de diversidade florística, de acordo com as diretrizes de Ribeiro e Walter (2008) (SANO et al., 2019a). Estas 19 subdivisões apresentadas pelos autores podem ser úteis para realizar o mapeamento da vegetação separadamente em cada uma das regiões, diminuindo as confusões espectrais decorrentes, por exemplo, de variações de umidade no solo e vegetação, fenologia, exposição solar, formação edáfica, etc.

\subsection{Dados de Sensoriamento Remoto}

Como mencionado, um grande problema para o mapeamento de áreas naturais, principalmente do bioma Cerrado, é em relação à diferenciação dos tipos de vegetação. Em diversos trabalhos (COSTA; FONSECA; KORTING, 2014; MÜLLER et al., 2015; SCHWIEDER et al., 2016), bem como nas iniciativas mencionadas neste estudo que utilizaram imagens de média resolução espacial $(30 \mathrm{~m})$, o nível de semântica (legenda) da classificação diferencia vegetação florestal de não florestal com alta exatidão (acima de 80\%), porém a confusão de classificação entre as diversas classes savânicas e campestres ainda permanece elevada. No geral, os maiores erros de classificação são encontrados na distinção entre estas fisionomias, como também com outras classes, como as pastagens, devido ao alto grau de semelhança espectral entre os alvos. Vale ressaltar que, para o Cerrado, confusões desse tipo ocorrem mesmo em mapeamentos atuais, resultando na superestimação do percentual de remanescentes naturais (não antrópicos) ao se interpretar o dado, como apontado pelo MMA na iniciativa do PROBIO e por Sano et al., (2019b) nos resultados do TerraClass Cerrado. Isso ocorre, especialmente no bioma Cerrado, visto que as fitofisionomias campestres são pastagens naturais e, apesar de serem consideradas como naturais, são destinadas ao uso antrópico.

A utilização de dados de alta resolução espacial $(4-10 \mathrm{~m})$ para discriminar essas classes fitofisiônomicas (PINHEIRO; DURIGAN, 2009; TEIXEIRA et al., 2015; GIROLAMO NETO; FONSECA; KÖRTING, 2017; GIROLAMO NETO, 2018) apresenta um ganho significativo de informação para a separação das diversas classes do Cerrado. Entretanto, o volume de dados produzidos necessita de esforços e novas metodologias para o processamento desta informação em uma escala a nível de bioma. Nesse quesito, pode-se destacar o mapeamento da FBDS com classificação de cenas RapidEye de $5 \mathrm{~m}$ de resolução espacial, embora a diferenciação fitofisionômica não tenha ocorrido em níveis mais específicos. Portanto, séries temporais de sensores de alta a moderada resolução espacial são importantes para separar classes que apresentam sazonalidade bem definida durante o ano, como as áreas campestres (JACON et al., 2017), assim como identificar e mapear áreas com queimadas recorrentes, como os campos de Murundus. Novas constelações de satélite como as da série Planet ( $3 \mathrm{~m}$ de resolução espacial, 4 bandas multiespectrais), que conta com 130 satélites (revisita diária) e de radar SAOCOM 1A e 1B (7-100 m de resolução espacial, banda L, revisita a cada 8 dias) podem ajudar a resolver as diferenças entre classes de níveis hierárquicos mais detalhados.

Dados auxiliares podem ser utilizados para o aprimoramento dos mapeamentos, como os índices de vegetação utilizados na maioria das iniciativas, modelos de mistura (PRODES), e demais dados ambientais. Apesar da vasta possibilidade desses índices encontrados na literatura (XUE; SU, 2017), os principais índices utilizados são NDVI (Normalized Difference Vegetation Index) e EVI (Enhanced Vegetation Index), com os sensores MODIS e os da série Landsat (FERREIRA et al., 2003, 2011; BAYMA; SANO, 2015), sendo que o primeiro possui produtos de índices de vegetação prontos para uso. Por exemplo, os produtos MOD13 e MYD13, dos satélites Terra/Aqua, respectivamente, são composições pré-processadas (georreferenciadas e em reflectância de superfície) e livres de nuvens. Já as imagens da série Landsat possuem o maior período de imageamento terrestre, desde 1985 e com resolução espacial de $30 \mathrm{~m}$, permitindo, assim, análises multitemporais de mudanças de uso e cobertura da terra em média resolução espacial.

Em relação às bandas espectrais, o infravermelho próximo, red-edge e infravermelho médio são comumente utilizados por serem faixas do espectro que capturam diferenças na estrutura do dossel devido às mudanças no índice de área foliar, conteúdo de água e clorofila, além das contribuições de materiais não fotossinteticamente ativos, especialmente observados na estação seca e na vegetação herbácea (TONIOL et al., 2017). Além das variações espectrais, índices de vegetação como, além dos já citados NDVI e EVI, o NDWI (Normalized Difference Water Index) e o NDII (Normalized Difference Infrared Index) são alguns dos 
mais importantes (HILL, 2013; TONIOL et al., 2017), pois estão relacionados às diferenças na estrutura do dossel e ao conteúdo de água nas folhas. Vários índices de vegetação bem estabelecidos podem ser calculados a partir das bandas multiespectrais do Sentinel-2 para aplicações em regiões savânicas (HILL, 2013).

Diferenças na sensibilidade de diversos índices de vegetação são observadas dependendo do estado de umidade, cobertura de árvores e tipo de fitofisionomia. Assim, séries temporais são necessárias para capturar completamente os estados e as mudanças espectrais, uma vez que formações campestres e savânicas têm níveis elevados níveis de variação espectral e fenológica (HILL, 2013). No entanto, de acordo com Toniol et al., (2017), a discriminação de classes no Cerrado é geralmente facilitada na estação seca, sendo necessária a utilização de um maior número de métricas (bandas espectrais ou índices de vegetação) na classificação da vegetação durante a estação chuvosa devido a maior confusão espectral com a maior homogeneização entre o gradiente de classes nesse período.

A dificuldade da diferenciação das parcelas vegetais também é um impeditivo no entendimento da natureza e extensão dos limites ecossistêmicos, visto que implicam diretamente na forma de manejo e na conservação da biodiversidade local. Essas transições, chamadas ecótonos, possuem alta complexidade ambiental, troca de espécies entre as comunidades bióticas e hiperdinâmica da vegetação ao agregar características de ambos ecossistemas. É o caso das transições Cerrado-Amazônia e Cerrado-Caatinga, que possuem grandes áreas e são representadas nos mapas oficiais simplesmente como uma linha para delimitação (MARQUES et al., 2020).

Abade et al. (2015) utilizaram o produto MOD09Q1 (série temporal do NDVI, sensor MODIS) no período 2011-2013 para mapear a vegetação nativa e exótica na zona de transição Cerrado-Caatinga, por meio do classificador SVM (Support Vector Machine) e obtiveram exatidão de 80,75\% de seis classes mapeadas (água, agricultura, pastagem, floresta estacional decidual, floresta estacional semidecidual e Cerrado). Os autores apontaram que os efeitos fenológicos são um dos maiores desafios no estudo de savanas e regiões semiáridas. Marques et al. (2020) analisaram mais de 30 anos da transição Cerrado-Amazônia, por meio de imagens TM/Landsat 5, técnicas de mistura espectral e classificação automática. Os autores concluíram que essas áreas registraram taxas de desmatamento maiores que as florestas e savanas em cada bioma individualmente. Ainda de acordo com os autores, esse limite deve ser redefinido por uma zona de transição complexa de aproximadamente $250 \mathrm{~km}$.

\subsection{Técnicas e métodos}

As técnicas e processamentos de classificação de imagens têm evoluído em conjunto com o desenvolvimento tecnológico e computacional. Algoritmos amplamente utilizados, como o MaxVer (Conservação Internacional), ISOSEG (TerraClass Cerrado), entre outros, começam a abrir espaço para técnicas de Machine Learning, algoritmos mais robustos como as árvores de decisão (MapBiomas) e ao conceito de mineração de dados. Atualmente, o incremento de novos dados e métricas em técnicas de classificação tornou-se um aspecto diferencial, visto que esses dados são produzidos em uma escala temporal cada vez menor. Ter ferramentas que auxiliam na análise de um volume crescente de dados (big data) em um curto espaço de tempo é uma realidade, seja por meio de técnicas de mineração de dados (data mining), inteligência artificial e computação profunda (deep learning), ou por meio de plataformas de computação em nuvem (cloud computing), como o Google Earth Engine (SOUZA MENDES et al., 2019; NEVES et al., 2020).

Técnicas de computação de aprendizagem profunda são promissoras para desenvolver uma segmentação semântica das classes do Cerrado. Em uma análise experimental, Neves et al., (2020) comparam a análise visual do sensor WorldView-II com a desenvolvida pela rede neural de convolução completa ( $U$ NET) e observaram que o nível de exatidão foi estatisticamente similar em ambos os casos (81\%; $90 \% ; 88 \%$ para as classes de campo, savana e floresta, respectivamente). As confusões foram observadas na transição entre classes cujas densidades de indivíduos arbóreos/arbustivos aumentaram gradativamente. Estas técnicas de computação podem ser ampliadas para realizar a segmentação e classificação de fisionomias em níveis hierárquicos mais detalhados, utilizando-se também de modificações na arquitetura da rede para integrar outras fontes de dados de forma sinérgica, como de Radar e ópticas. Por exemplo, Souza Mendes et al., (2019) observaram que informações de dados de radar (ALOS/PALSAR-2, full e dual polarimetric, TanDEM-X e 
Sentinel-1) e ópticos (Sentinel-2) quando combinados apresentaram um ganho de exatidão global significativo na classificação durante as estações seca e chuvosa (exatidão de $81,9 \%$ ), embora na estação seca a exatidão global não tenha apresentado diferença entre o uso do Sentinel-2 e o uso combinado de dados. Entretanto, os autores empregaram a abordagem de aprendizado de máquina e não de aprendizado profundo. Dentre as classes, os dados de Radar (TanDEM-X e Sentinel-1, banda X e banda-C, respectivamente) apresentaram exatidão superior aos dos dados ópticos para mapear as Matas de Galeria, embora estes sejam inferiores para mapear as classes de Cerradão e Cerrado Denso (SOUZA MENDES et al., 2019). Para a classe de floresta secundária, dados de radar dual-pol (HH+HV) ALOS/PALSAR-2 também apresentaram maior exatidão do que os dados do Sentinel-2.

Dessa forma, classificadores baseados em árvores de decisão ou que envolvam critérios condicionais ou semânticos são úteis para separar melhor determinadas classes de acordo com a aptidão específica de cada tipo de dado e em concordância com as características geomorfológicas, fisiológicas e edáficas de cada fitofisionomia. Por exemplo, sabe-se que o Cerrado rupestre ocorre em altitudes superiores a $900 \mathrm{~m}$ e áreas com maior declividade e são raros fora destas condições (RIBEIRO; WALTER, 2008), logo, um modelo digital de elevação pode ser usado para refinar a classificação destas áreas. Outro exemplo que causa bastante confusão é como as Veredas podem ser separadas a partir de dados de radar por sua maior sensibilidade às áreas alagáveis e/ou inundáveis (GIROLAMO NETO, 2018), ou sensores de alta resolução espacial como o CBERS4A/WPM ( 8 metros de resolução espacial em 4 bandas multiespectrais, 2 metros de resolução espacial em 1 banda pancromática, resolução temporal de 31 dias). Do mesmo modo, técnicas de aprendizado profundo de imagens de altíssima resolução podem ser usadas para identificar as copas de palmeiras nos Palmeirais (Buritizais, Babaçuais e Guerobais) com precisão nestes locais (WAGNER et al., 2020). Dados de LiDAR como os do GEDI (Global Ecosystem Dynamics Investigation) podem ser úteis para separar fisionomias pela altura média de copas, como as áreas de Cerradão e de Cerrado senso restrito devido à maior altura média.

\subsection{Geração big data}

A abundância de dados gera desafios no desenvolvimento de rotinas que visem a utilização desse volume de dados, em grandes escalas espaciais e com boa qualidade na filtragem de nuvens. Esse desafio na utilização de dados pode ser observado, por exemplo, no percentual de downloads dos produtos provenientes das missões Sentinel, em que apenas $0.3 \%$ de todos os downloads realizados em 2019 foram observados na América do Sul, indicando que os usuários optam por baixar uma seleção mais específica de dados ao invés de um grande volume (COPERNICUS, 2020). Portanto, é fundamental o estabelecimento de métodos de análises para o melhor aproveitamento das potencialidades que essas informações em alta frequência de revisita podem oferecer no monitoramento e mapeamento do Cerrado, especialmente para projetos operacionais ou sistemáticos.

Um exemplo é a utilização de plataformas como o Google Earth Engine (GEE), o qual baseia-se em armazenamento em nuvem e facilita o acesso a recursos computacionais de alta performance e processamento de grandes conjuntos de dados geoespaciais. Ainda, a plataforma foi projetada para auxiliar na disseminação de resultados científicos (GORELICK et al., 2017), possuindo um extenso catálogo de dados, com uma grande variedade de imagens aéreas e de satélite, variáveis ambientais, dados de tempo e clima, cobertura da terra, topográficos e socioeconômicos, prontos para uso. Outra possibilidade do GEE é a inserção de dados na plataforma, permitindo que o usuário utilize seus próprios dados para realizar análises, tudo isso em um ambiente de desenvolvimento integrado (API) que suporta a implementação de algoritmos de análise e processamento de dados geoespaciais nas linguagens Javascript e Python (GORELICK, 2013). Nesse sentido, abordagens metodológicas que utilizam diferentes linguagens de programação (Python, $\mathrm{R})$ crescem a cada dia, permitindo a criação e o compartilhamento de pacotes de análise prontos, o que amplia o acesso até mesmo para usuários com pouca experiência em programação.

Por fim, considerando a grande extensão do bioma Cerrado, sugere-se o esforço na formação de extensas redes de observação de campo e compartilhamento de dados. Informações dessa natureza são primordiais para o desenvolvimento de metodologias e algoritmos mais robustos, bem como na realização de pesquisas e avaliação de novas tecnologias de Sensoriamento Remoto. Nesse sentido, a tendência é nos 
aproximarmos cada vez mais de uma análise inteligente, que visa o potencial de identificação e discriminação de imagens de modo semelhante à fotointerpretação.

Além disso, a nova geração de sistemas sensores tem se revelado promissora, com bandas alocadas em intervalos de comprimento de onda específicos (MSI/Sentinel-2), como as bandas espectrais do red-edge que são particularmente úteis na diferenciação da vegetação, pois apresentam maior variação nesses comprimentos de onda, e pixels cada vez menores, o que atenua as transições entre os alvos e as lacunas temporais. Dentre as promessas futuras destacam-se o Landsat 9 (lançamento previsto para 2021), que juntamente com o Landsat 8 reduzirá a janela temporal da série de 16 para 8 dias. Ainda, novas possibilidades também estão previstas no universo do Sensoriamento Remoto Hiperespectral, com o lançamento do sensor alemão EnMap (Environmental Mapping and Analysis) e o americano HyspIRI (Hyperspectral Infrared Imager), com previsão para 2021 e 2023, respectivamente.

\section{CONCLUSÃO}

Grandes iniciativas surgiram no âmbito do mapeamento da vegetação do Cerrado ao longo dos últimos 20 anos, o que evidencia o aumento dos esforços para a compreensão das dinâmicas de uso e cobertura da terra no bioma, principalmente na última década. Os sensores atuais desafiam a temporalidade, visto que a maioria das iniciativas utilizam dados dos satélites Landsat e sensor MODIS. Este último, apesar de sua moderada a baixa resolução espacial $(250 \mathrm{~m}-1 \mathrm{~km})$, apresenta uma variedade de dados pré processados. Já o Landsat, de média resolução espacial $(30 \mathrm{~m})$ e com amplitude temporal superior a 30 anos, foi o principal dado utilizado pelas iniciativas apresentadas neste estudo que avaliaram o status da vegetação do bioma. Dentre a nova geração de sensores, o uso de dados da constelação Sentinel representa uma oportunidade promissora para o estabelecimento de novas iniciativas. Da mesma forma, a combinação de imagens de alta resolução temporal com técnicas robustas de classificação é essencial para o avanço do conhecimento no que diz respeito à diferenciação fitofisionômica do Cerrado.

A diversidade de técnicas de classificação evoluiu de modo a nos aproximar cada vez mais de uma análise inteligente, que visa o potencial de identificação e discriminação de imagens semelhantes à fotointerpretação. Isso tende a fornecer subsídios consistentes para o enfrentamento dos desafios ainda existentes no que diz respeito a um mapeamento confiável das diferentes classes de vegetação do Cerrado, superando os obstáculos impostos pelas semelhanças espectrais de fisionomias savânicas, campestres e outros tipos de uso da terra, como as pastagens, bem como dos efeitos significativos das variações sazonais na fenologia da vegetação característica do bioma. Outro ponto que merece destaque é o avanço da informação para além do pixel, e como esta ciência tem sido direcionada para uma abordagem mais holística, envolvendo interdisciplinaridade e elementos de diversas áreas do conhecimento.

Assim, no esforço de explorar estrategicamente novas oportunidades para o mapeamento e monitoramento do bioma Cerrado, são identificados os seguintes focos de pesquisa: 1) Utilizar novos e aprimorados conjuntos de dados de Sensoriamento Remoto que podem fornecer informações mais detalhadas sobre a estrutura, fisionomia e sazonalidade observadas no bioma; 2) Integração de sensores, como, por exemplo, óptico e radar, e dados auxiliares, que podem melhorar a exatidão nos resultados; 3) Uso de algoritmos aplicados em grande volume de dados e de séries temporais; 4) Desenvolvimento de rotinas adequadas para mapear, monitorar, e utilizar séries temporais de imagens com boa qualidade; 5) Desenvolvimento, manutenção e expansão de redes observacionais de campo e compartilhamento de dados. Essas direções de pesquisa tem o potencial de preencher as atuais lacunas do conhecimento e avançar o horizonte de pesquisa no âmbito do Cerrado.

O mapeamento e monitoramento preciso da vegetação do Cerrado, tanto em suas fisionomias como em áreas convertidas, são necessários para identificar e designar novas áreas prioritárias para a conservação, e também para aperfeiçoar o entendimento das dinâmicas de uso e ocupação da terra no bioma e seus impactos no balanço de carbono, ciclagem de nutrientes e recursos hídricos. Portanto, é indispensável quantificar o percentual de remanescentes da vegetação do Cerrado por tipo de fitofisionomia, avaliar o grau de ameaça individual de cada uma, bem como compreender o grau de impacto que cada agente exerce em cada fitofisionomia. Nesse sentido, o Sensoriamento Remoto aliado à expertise dos cientistas que dominam o 
conhecimento desse importante bioma é crucial na tentativa de conter as elevadas taxas de antropismo no bioma.

\section{Agradecimentos}

O estudo foi apoiado pelo Conselho Nacional de Desenvolvimento Científico e Tecnológico (CNPq/IBAMA-PrevFogo - 441942/2018-0, CNPq/Monitoramento dos biomas brasileiros por satélite construção de novas capacidades - 444418/2018-0, CNPq Universal - 431172/2018-8, bolsas 140378/20189, 444327/2018-5, 380716/2019-4 e 303299/2018-5) e Fundação de Amparo à Pesquisa do Estado de São Paulo (FAPESP - bolsa 18/14423-4).

\section{Contribuição dos Autores}

A primeira autora foi responsável pela administração e coordenação do projeto, pela conceptualização, curadoria dos dados, análise formal, investigação, metodologia, recursos, software, visualização, redação em todos os níveis (minuta inicial, revisão e edição). O segundo autor contribuiu com a conceptualização, recursos, visualização, redação (revisão e edição). O terceiro autor auxiliou na conceptualização, recursos, curadoria dos dados, investigação, redação em todos os níveis. A quarta autora forneceu recursos, visualização e redação (revisão e edição). Os demais autores participaram da redação (revisão e edição), sendo o último autor, o responsável pela supervisão.

\section{Conflitos de Interesse}

Os autores declaram que não há conflito de interesse.

\section{Referências}

ABADE, N.; JÚNIOR, O.; GUIMARÃES, R.; DE OLIVEIRA, S. Comparative Analysis of MODIS TimeSeries Classification Using Support Vector Machines and Methods Based upon Distance and Similarity Measures in the Brazilian Cerrado-Caatinga Boundary. Remote Sensing, v. 7, n. 9, p. 12160-12191, 2015. DOI: $10.3390 /$ rs 70912160

ALVIM, P. T. Teoria sobre a formação dos campos cerrados. Revista Brasileira de Geografia, v. 16, p. 496498, 1954.

ARMANDO, M. S. O impacto do fogo na rebrota de algumas espécies de árvores do Cerrado. 1994. 74 p. Dissertação (Mestrado em Ecologia) - Instituto de Ciências Biológicas, Universidade de Brasília, Brasília, DF, 1994.

BAYMA, A. P.; SANO, E. E. Séries temporais de índices de vegetação (NDVI e EVI) do sensor MODIS para detecção de desmatamentos no bioma Cerrado. Boletim de Ciencias Geodesicas, v. 21, n. 4, p. 797-813, 2015. DOI: $10.1590 / \mathrm{S} 1982-21702015000400047$

BEARD, J. S. The Savanna Vegetation of Northern Tropical America. Ecological Monographs, v. 23, n. 2, p. 149-215, abr. 1953. DOI: $10.2307 / 1948518$

BEUCHLE, R.; GRECCHI, R. C.; SHIMABUKURO, Y. E.; SELIGER, R.; EVA, H. D.; SANO, E.; ACHARD, F. Land cover changes in the Brazilian Cerrado and Caatinga biomes from 1990 to 2010 based on a systematic remote sensing sampling approach. Applied Geography, v. 58, p. 116-127, 2015. DOI: 10.1016/j.apgeog.2015.01.017

BIGARELlA, J. J.; ANDRADE-LIMA, D.; RIEHS, P. J. Considerações a respeito das mudanças paleoambientais na distribuição de algumas espécies vegetais e animais no Brasil. Anais Academia Brasileira de Ciências, v. 47, p. 411-464, 1975.

BRASIL. Código Florestal - Lei no 12.651, de 25 de maio de 2012. Disponível em: 
<http://www.planalto.gov.br/ccivil_03/_ato2011-2014/2012/lei/L12651compilado.htm>. Acesso em: 1 ago. 2020.

CARVALHO, L. M. T. Mapeamento da flora nativa e das florestas de produção do Estado de Minas Gerais: procedimentos metodológicos e resultados parciais. (INPE, Ed.) In: Simpósio Brasileiro de Sensoriamento Remoto, XII, 2005, Goiânia. Anais... Goiânia: INPE, 2005

COPERNICUS. Copernicus Sentinel data access annual report 2019. 2020. Disponível em: <https://scihub.copernicus.eu/twiki/pub/SciHubWebPortal/AnnualReport2019/COPE-SERCO-RP-200570_-_Sentinel_Data_Access_Annual_Report_Y2019_v1.0.pdf>. Acesso em: 12 nov. 2020

COSTA, W. S.; FONSECA, L. M. G.; KORTING, T. S. Mapping Grasslands Formations and Cultivated Pastures in the Brazilian Cerrado Using Data Mining. (IARIA, Ed.) In: GEOProcessing 2014: International Conference on Advanced Geographic Information Systems, Applications, and Services, 2014, Barcelona. Anais... Barcelona: 2014. DOI: 10.13140/2.1.2986.2721

COUTINHO, L. M. O conceito de Cerrado. Revista Brasileira de Botânica, v. 1, p. 17-23, 1978.

EITEN, G. The Cerrado Vegetation Of Brazil. The Botanical Review. Botanical Review, v. 38, n. 2, p. 201$327,1972$.

EITEN, G. Vegetação do Cerrado. In: Cerrado: caracterização, ocupação e perspectivas. Brasília: UnB/SEMATEC, 1994.

EMBRAPA. Sobre o MATOPIBA. Disponível em: <https://www.embrapa.br/tema-matopiba/sobre-o-tema>. Acesso em: 27 jul. 2020.

ESCOBAR, I. P.; OLIVEIRA, S.; LIMA, S. P. S.; PRADO, R.; FERREIRA, A. T. A. Reprocessamento digital das imagens SLAR geradas pelos projetos RADAM e RADAMBRASIL-projeto RADAM-D. In: Simpósio Brasileiro de Sensoriamento Remoto, XII, 2005, Goiânia. Anais... Goiânia: INPE, 2005.

EVA, H. D.; BELWARD, A. S.; DE MIRANDA, E. E.; DI BELLA, C. M.; GOND, V.; HUBER, O.; JONES, S.; SGRENZAROLI, M.; FRITZ, S. A land cover map of South America. Global Change Biology, v. 10, n. 5, p. 731-744, 2004. DOI: 10.1111/j.1529-8817.2003.00774.x

FARIA, A. S. Detecção automática de desmatamentos no bioma cerrado: desafios para o monitoramento sistemático. 2018. Tese (Doutorado em Ciências Ambientais) - Universidade Federal de Goiás (UFG), Goiânia, Goiás, 2018.

FBDS. Desenvolvimento Rural Sustentável. Disponível em: <https://www.fbds.org.br/article.php3?id_article=594>. Acesso em: 27 jul. 2020.

FBDS. Download dados FBDS. Disponível em: <http://geo.fbds.org.br/>. Acesso em: jul. 2020

FERREIRA, L. G.; ASNER, G. P.; KNAPP, D. E.; DAVIDSON, E. A.; COE, M.; BUSTAMANTE, M. C.; DE OLIVEIRA, E. L. Equivalent water thickness in savanna ecosystems: MODIS estimates based on ground and EO-1 Hyperion data. International Journal of Remote Sensing, 2011. DOI: $10.1080 / 01431161.2010 .523731$

FERREIRA, L. G.; YOSHIOKA, H.; HUETE, A.; SANO, E. E. Seasonal landscape and spectral vegetation index dynamics in the Brazilian Cerrado: An analysis within the Large-Scale Biosphere-Atmosphere Experiment in Amazônia (LBA). Remote Sensing of Environment, 2003. DOI: 10.1016/j.rse.2002.09.003

GIBBS, H. K.; RAUSCH, L.; MUNGER, J.; SCHELLY, I.; MORTON, D. C.; NOOJIPADY, P.; SOARESFILHO, B.; BARRETO, P.; MICOL, L.; WALKER, N. F. Brazil's Soy Moratorium: Supply-chain governance is needed to avoid deforestation. Science, v. 347, n. 6220, p. 377-378, 2015. DOI: 10.1126/science.aaa0181

GIROLAMO NETO, C. Identificação de fitofisionomias de Cerrado no Parque Nacional de Brasília utilizando Random Forest aplicado a imagens de alta e média resoluções espaciais. 2018. Tese (Doutorado em Sensoriamento Remoto) - Instituto de Pesquisas Espaciais (INPE), São José dos Campos, São Paulo, 2018.

GIROLAMO NETO, C.; FONSECA, L. M. G.; KÖRTING, T. S. Assessment of texture features for Brazilian 
savanna classification: A case study in Brasilia national park. In: Proceedings of the Brazilian Symposium on GeoInformatics, 2017, Salvador, Bahia. Anais... Salvador, Bahia: 2017

GÓES FILHO, L.; VELOSO, H. P. Fitogeografia Brasileira - Classificação Fisionômico-Ecológica da Vegetação Neotropical. 1982.

GOODLAND, R.; FERRI, M. G. Ecologia do Cerrado. Belo Horizonte: Edusp Itatiaia, 1979. 193 p.

GORELICK, N. Google Earth Engine. In: EGU General Assembly Conference Abstracts, 2013, Vienna, Austria. Anais... Vienna, Austria: 2013

GORELICK, N.; HANCHER, M.; DIXON, M.; ILYUSHCHENKO, S.; THAU, D.; MOORE, R. Google Earth Engine: Planetary-scale geospatial analysis for everyone. Remote Sensing of Environment, v. 202, p. 18-27, 2017. DOI: 10.1016/j.rse.2017.06.031

HANSEN, M. C.; POTAPOV, P. V.; MOORE, R.; HANCHER, M.; TURUBANOVA, S. A.; TYUKAVINA, A.; THAU, D.; STEHMAN, S. V.; GOETZ, S. J.; LOVELAND, T. R.; KOMMAREDDY, A.; EGOROV, A.; CHINI, L.; JUSTICE, C. O.; TOWNSHEND, J. R. G. Global Forest Change. Disponível em: <https://earthenginepartners.appspot.com/science-2013-global-forest>.

HANSEN, M. C.; POTAPOV, P. V.; MOORE, R.; HANCHER, M.; TURUBANOVA, S. A.; TYUKAVINA, A.; THAU, D.; STEHMAN, S. V.; GOETZ, S. J.; LOVELAND, T. R.; KOMMAREDDY, A.; EGOROV, A.; CHINI, L.; JUSTICE, C. O.; TOWNSHEND, J. R. G. High-resolution global maps of 21 st-century forest cover change. Science, v. 342, n. 6160, p. 850-853, 2013. DOI: 10.1126/science.1244693

HILL, M. J. Vegetation index suites as indicators of vegetation state in grassland and savanna: An analysis with simulated SENTINEL 2 data for a North American transect. Remote Sensing of Environment, v. 137, p. 94-111, out. 2013. DOI: 10.1016/j.rse.2013.06.004

IBGE. Manual Técnico da Vegetação Brasileira. Rio de Janeiro. 1992.

IBGE. Desbravar, conhecer, mapear: memórias do Projeto Radam / RadamBrasil. Rio de Janeiro: IBGE, 2018. ISBN(978-85-240-4471-7).

IBGE. Biblioteca online - IBGE. Disponível em: <https://biblioteca.ibge.gov.br/>. Acesso em: jul. 2020

INPE. TerraClass Cerrado. Disponível em: <http://www.dpi.inpe.br/tccerrado/>. Acesso em: jul. 2020

INPE. Projeto TerraClass Cerrado Mapeamento do Uso e Cobertura Vegetal do Cerrado. Disponível em: <http://www.dpi.inpe.br/tccerrado/index.php?mais=1>. Acesso em: 27 jul. $2020 \mathrm{~b}$.

INPE. TerraBrasilis - Dashboard de Desmatamento. Disponível em: <http://terrabrasilis.dpi.inpe.br/app/dashboard/deforestation/biomes/cerrado/increments>. Acesso em: 27 jul. 2020c.

INPE. TerraBrasilis - DETER Avisos. Disponível em: <http://terrabrasilis.dpi.inpe.br/app/map/alerts?hl=ptbr>. Acesso em: 27 jul. 2020d.

INPE. Projeto DETER. Disponível em: <http://www.inpe.br/cra/projetos_pesquisas/deter.php>. Acesso em: 27 jul. 2020e.

JACON, A. D.; GALVÃO, L. S.; DOS SANTOS, J. R.; SANO, E. E. Seasonal characterization and discrimination of savannah physiognomies in Brazil using hyperspectral metrics from Hyperion/EO-1. International Journal of Remote Sensing, v. 38, n. 15, p. 4494-4516, 2017. DOI: 10.1080/01431161.2017.1320443

KLINK, C. A.; MACHADO, R. B. A conservação do Cerrado brasileiro. MEGADIVERSIDADE, v. 1, p. 147-155, 2005.

KRONKA, F. J. N.; NALON, M. A.; MATSUKUMA, C. K.; KANASHIRO, M. M.; YWANE, M. S. S.-I.; LIMA, L. M. P. R.; GUILLAUMON, J. R.; BARRADAS, A. M. F.; PAVÃO, M.; MANETTI, L. A.; BORGO, S. C. Monitoramento da vegetação natural e do reflorestamento no Estado de São Paulo. In: Simpósio Brasileiro de Sensoriamento Remoto, XII, Goiânia, Brasil, 2005, Anais... 2005.

LAPIG. SIAD-CERRADO. Disponível em: <https://www.lapig.iesa.ufg.br/lapig/index.php/produtos/14menu-principal/projetos/38-siad-cerrado>. Acesso em: jul. 2020. 
MACHADO, R. B.; RAMOS NETO, M. B.; PEREIRA, P. G. P.; CALDAS, E. F.; GONÇALVES, D. A.; SANTOS, N. A. S.; TABOR, K.; STEININGER, M.; NETO, M. G. P.; CALDAS, E. F.; GONÇALVES, D. A.; SANTOS, N. A. S.; TABOR, K.; STEININGER, M. Estimativas de perda da área do Cerrado brasileiro. Relatório técnico não publicado. Conservação Internacional, Brasília. 2004.

MAPBIOMAS. Metodologia - MapBiomas. Disponível em: <https://mapbiomas.org/atbd---entenda-cadaetapa>. Acesso em: 27 jul. 2020a.

MAPBIOMAS. Códigos e Ferramentas. Disponível em: <https://mapbiomas.org/ferramentas>. Acesso em: jul. 2020

MARQUES, E. Q.; MARIMON-JUNIOR, B. H.; MARIMON, B. S.; MATRICARDI, E. A. T.; MEWS, H. A.; COLLI, G. R. Redefining the Cerrado-Amazonia transition: implications for conservation. Biodiversity and Conservation, v. 29, n. 5, p. 1501-1517, 2020. DOI: 10.1007/s10531-019-01720-z

MAURANO, L. E. P.; ALMEIDA, C. A. DE; MEIRA, M. B. Monitoramento do desmatamento do cerrado brasileiro por satélite prodes cerrado. (INPE, Ed.)In: XIX Simposio Brasileiro de Sensoramento Remoto, 2019, Santos, São Paulo. Anais... Santos, São Paulo: INPE, 2019

MIRANDA, H. S.; SILVA, E. P.; MIRANDA, A. C. Comportamento do fogo em queimadas de campo sujo. In: Congresso de Ecologia do Brasil, 3, 1996, Anais... 1996

MISTRY, J.; BIZERRIL, M. Por Que é Importante Entender as Inter-Relações entre Pessoas, Fogo e Áreas Protegidas? Biodiversidade Brasileira, v. 2, p. 40-49, 2011.

MMA. Mapeamento de Cobertura Vegetal do Bioma Cerrado - Relatorio Final. Edital Probio 02/2004.2007.

MMA. Plano de Ação para Prevenção e Controle do Desmatamento e das Queimadas no Cerrado PPCerrado. Brasília. 2009.

MMA. Mapeamento do Uso e Cobertura da Terra do Cerrado - Projeto TerraClass Cerrado 2013. Brasília. 2015a.

MMA. PMDBBS: Monitoramento do bioma Cerrado do período 2010-2011. Brasília. 2015b.

MMA. O Bioma Cerrado. Disponível em: <http://www.mma.gov.br/biomas/cerrado>. Acesso em: 27 jul. 2020a.

MMA. Download de dados geográficos. Disponível em: <http://mapas.mma.gov.br/i3geo/datadownload.htm>. Acesso em: jul. 2020

MMA. Download dados PMDBBS. Disponível em: <https://www.mma.gov.br/projeto-de-monitoramentodo-desmatamento-nos-biomas-brasileiros-por-satelite-pmdbbs.html>. Acesso em: jul. 2020

MÜLLER, H.; RUFIN, P.; GRIFFITHS, P.; JOSÉ BARROS SIQUEIRA, A.; HOSTERT, P. Mining dense Landsat time series for separating cropland and pasture in a heterogeneous Brazilian savanna landscape. (INPE, Ed.)In: XVII Simpósio Brasileiro de Sensoriamento Remoto, 2015, João Pessoa, Paraíba. Anais... João Pessoa, Paraíba: INPE, 2015

MYERS, N.; MITTERMEIER, R. A.; MITTERMEIER, C. G.; FONSECA, G. A. B. DA; KENT, J. Biodiversity hotspots for conservation priorities. Nature, v. 403, p. 853-858, 2000.

NEVES, A. K.; KÖRTING, T. S.; FONSECA, L. M. G.; GIROLAMO NETO, C. D.; WITTICH, D.; COSTA, G. A. O. P.; HEIPKE, C. Semantic segmentation of brazilian savanna vegetation using high spatial resolution satellite data and u-net. ISPRS Annals of Photogrammetry, Remote Sensing and Spatial Information Sciences, v. V-3-2020, p. 505-511, 3 ago. 2020. DOI: 10.5194/isprs-annals-V-3-2020-5052020

PINHEIRO, E. DA S.; DURIGAN, G. Dinâmica espaço-temporal (1962-2006) das fitofisionomias em unidade de conservação do Cerrado no sudeste do Brasil. Revista Brasileira de Botânica, v. 32, n. 3, p. 441-454, 2009.

REIS, T.; RUSSO, G.; RIBEIRO, V.; MOUTINHO, P.; STABILE, M.; ALENCAR, A.; SILVA, D. Oportunidades e desafios climáticos no Cerrado brasileiro. 2017. 
RIBEIRO, J. F.; WALTER, B. M. T. As principais fitofisionomias do bioma Cerrado. In: Cerrado: Ecologia e flora. 1. ed. Planaltina: EMBRAPA Cerrados/EMBRAPA Informação Tecnológica, 2008. p. 152-212.

RIBEIRO, J. F.; WALTER, T. Fitofisionomias do bioma Cerrado. In: SANO, S. M.; ALMEIDA, S. P. (Eds.). Cerrado: Ambiente e flora. Brasília: EMBRAPA Cerrados, 1998.

SANO, E. E.; RODRIGUES, A. A.; MARTINS, E. S.; BETTIOL, G. M.; BUSTAMANTE, M. M. C.; BEZERRA, A. S.; COUTO, A. F.; VASCONCELOS, V.; SCHÜLER, J.; BOLFE, E. L. Cerrado ecoregions: A spatial framework to assess and prioritize Brazilian savanna environmental diversity for conservation. Journal of Environmental Management, v. 232, p. 818-828, 2019a. DOI: 10.1016/j.jenvman.2018.11.108

SANO, E. E.; ROSA, R.; BRITO, J. L. S.; FERREIRA, L. G. Mapeamento de Cobertura Vegetal do Bioma Cerrado: estratégias e resultados. Planaltina DF. 2007.

SANO, E. E.; ROSA, R.; BRITO, J. L. S. S.; FERREIRA, L. G. Land cover mapping of the tropical savanna region in Brazil. Environmental Monitoring and Assessment, v. 166, n. 1-4, p. 113-124, 6 jul. 2010.

SANO, E. E.; ROSA, R.; SCARAMUZZA, C. A. DE M.; ADAMI, M.; BOLFE, E. L.; COUTINHO, A. C.; ESQUERDO, J. C. D. M.; MAURANO, L. E. P.; NARVAES, I. DA S.; FILHO, F. J. B. DE O.; DA SILVA, E. B.; VICTORIA, D. DE C.; FERREIRA, L. G.; BRITO, J. L. S.; BAYMA, A. P.; DE OLIVEIRA, G. H.; BAYMA-SILVA, G. Land use dynamics in the Brazilian Cerrado in the period from 2002 to 2013. Pesquisa Agropecuaria Brasileira, v. 54, 2019b. DOI: 10.1590/S16783921.pab2019.v54.00138

SCHWIEDER, M.; LEITÃO, P. J.; DA CUNHA BUSTAMANTE, M. M.; FERREIRA, L. G.; RABE, A.; HOSTERT, P. Mapping Brazilian savanna vegetation gradients with Landsat time series. International Journal of Applied Earth Observation and Geoinformation, v. 52, p. 361-370, 2016. DOI: 10.1016/j.jag.2016.06.019

SCOLFORO, J. R.; CARVALHO, L. M. T. Mapeamento e inventário da flora nativa e dos reflorestamentos de Minas Gerais. Lavras: UFLA, 2006. 288 p. ISBN(8587692313, 9788587692313).

SIMON, M. F.; GRETHER, R.; QUEIROZ, L. P.; SKEMA, C.; PENNINGTON, R. T.; HUGUES, C. E. Recent assembly of the Cerrado, a neotropical plant diversity hotspot, by in situ evolution of adaptations to fire. Proceedings of the National Academy of Sciences, v. 106, n. 48, 2009.

SOUZA MENDES, F.; BARON, D.; GEROLD, G.; LIESENBERG, V.; ERASMI, S. Optical and SAR Remote Sensing Synergism for Mapping Vegetation Types in the Endangered Cerrado/Amazon Ecotone of Nova Mutum-Mato Grosso. Remote Sensing, v. 11, n. 10, p. 1161, 15 maio 2019. DOI: $10.3390 / \mathrm{rs} 11101161$

STRASSBURG, B. B. N.; BROOKS, T.; FELTRAN-BARBIERI, R.; IRIBARREM, A.; CROUZEILLES, R.; LOYOLA, R.; LATAWIEC, A. E.; OLIVEIRA FILHO, F. J. B.; DE SCARAMUZZA, C. A. M.; SCARANO, F. R.; SOARES-FILHO, B.; BALMFORD, A. Moment of truth for the Cerrado hotspot. Nature Ecology and Evolution, v. 1, n. 4, p. 1-3, 2017. DOI: 10.1038/s41559-017-0099

TARDIN, A. T.; SANTOS, A. P.; NOVO, E. M. L. M. Uso de dados do LANDSAT no estudo do impacto da implantação de projetos agropecuários da Amazônia. 1977.

TARDIN, A. T.; SANTOS, A. P. DOS; LEE, D. C. L.; MAIA, F. C. S.; MENDONÇA, F. J.; ASSUNÇÃO, G. V.; RODRIGUES, J. E.; ABDON, M. DE M.; NOVAES, R. A.; CHEN, S. C.; DUARTE, V.; SHIMABUKURO, Y. E. Levantamento de áreas de desmatamento na Amazônia Legal através de imagens do satélite LANDSAT. 1979.

TEIXEIRA, L. R.; NUNES, G. M.; FINGER, Z.; SIQUEIRA, A. J. B. Potencialidades da Classificação Orientada a Objetos em Imagens SPOT5 no Mapeamento de Fitofisionomias do Cerrado. Revista ESPACIOS, v. 36, n. 20, 29 out. 2015.

TERRABRASILIS. Acesso aos dados PRODES e DETER. Disponível em: <http://terrabrasilis.dpi.inpe.br/>. Acesso em: jul. 2020

TONIOL, A. C.; GALVÃO, L. S.; PONZONI, F. J.; SANO, E. E.; DE JESUS AMORE, D. Potential of 
hyperspectral metrics and classifiers for mapping Brazilian savannas in the rainy and dry seasons. Remote Sensing Applications: Society and Environment, v. 8, p. 20-29, nov. 2017. DOI: 10.1016/j.rsase.2017.07.004

VELOSO, H. P.; RANGEL FILHO, A. L. R.; LIMA, J. C. A. Classificação da vegetação brasileira, adaptada a um sistema universal. Rio de Janeiro. 1991.

WAGNER, F. H.; DALAGNOL, R.; TAGLE CASAPIA, X.; STREHER, A. S.; PHILLIPS, O. L.; GLOOR, E.; ARAGÃO, L. E. O. C. Regional Mapping and Spatial Distribution Analysis of Canopy Palms in an Amazon Forest Using Deep Learning and VHR Images. Remote Sensing, v. 12, n. 14, p. 2225, 11 jul. 2020. DOI: $10.3390 /$ rs 12142225

WALTER, B. M. T. Fitofisionomias do bioma Cerrado: síntese terminológica e relações florísticas. 2006. Tese (Doutorado em Ecologia) - Universidade Federal de Brasília (UnB), Brasília, DF, 2006.

XUE, J.; SU, B. Significant Remote Sensing Vegetation Indices: A Review of Developments and Applications. Journal of Sensors, v. 2017, p. 1-17, 2017. DOI: 10.1155/2017/1353691

\section{Biografia dos Autores}

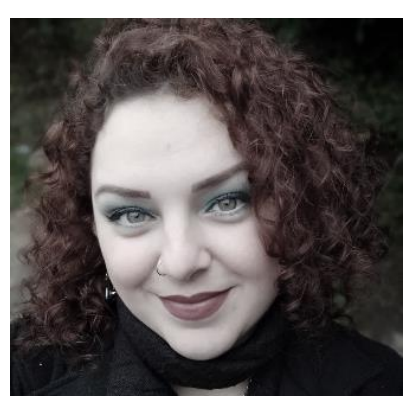

Marceli Terra nasceu no interior de São Paulo (1989). Recebeu o BSc em Ciências Ambientais (2014) e o MSc em Geociências Aplicadas (2017), ambos pela Universidade de Brasília (UnB). Atualmente realiza o $\mathrm{PhD}$ em Sensoriamento Remoto no Instituto Nacional de Pesquisas Espaciais (INPE) com estudo das fitofisionomias do Cerrado. Seus interesses de pesquisa são no uso de sensoriamento remoto e sistema de informações geográficas (SIG) para o monitoramento da vegetação, mudanças ambientais e na conservação do bioma Cerrado.

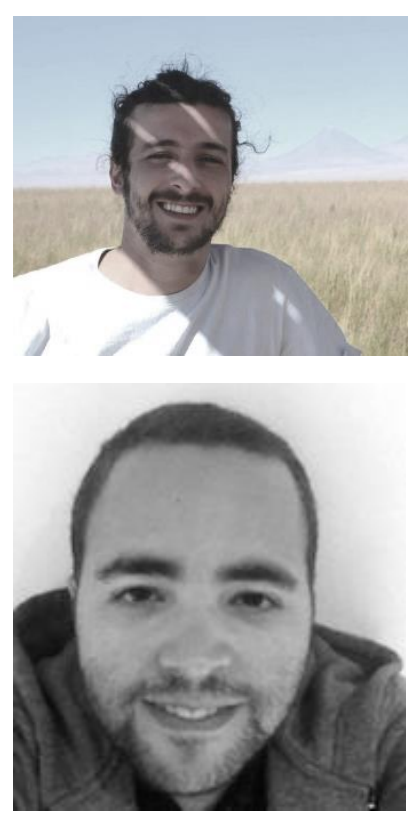

Henrique Luis Godinho Cassol é Engenheiro Florestal pela Universidade Federal de Santa Maria, Rio Grande do Sul, Brasil, em 2010, Mestre em Sensoriamento Remoto pela Universidade Federal do Rio Grande do Sul, Porto Alegre, Brasil, em 2013, e doutor em Sensoriamento Remoto pelo Instituto Nacional de Pesquisas Espaciais (INPE), São José dos Campos, Brasil, em 2017. Atualmente realiza pósdoutorado pela Fundação de Amparo à Pesquisa do Estado de São Paulo (Fapesp) na Amazônia de longa duração, projeto de balanço de carbono (CARBAM).

Khalil Ali Ganem nasceu no estado de Goiás e possui os títulos de Bacharel em Ciências Ambientais e Mestre em Geociências Aplicadas, ambos pela Universidade de Brasília (UnB). Possui experiência com mapeamento e monitoramento da vegetação usando técnicas de sensoriamento remoto, bem como na interpretação e coleta de dados para validação de mapas globais em diferentes ecossistemas da América do Sul. Atualmente é bolsista (PCI/CNPq) no Instituto Nacional de Pesquisas Espaciais (INPE) e seus interesses de pesquisa são no uso do sensoriamento remoto para investigar mudanças de uso e cobertura da terra, ciclo do carbono e comportamento sazonal da vegetação.

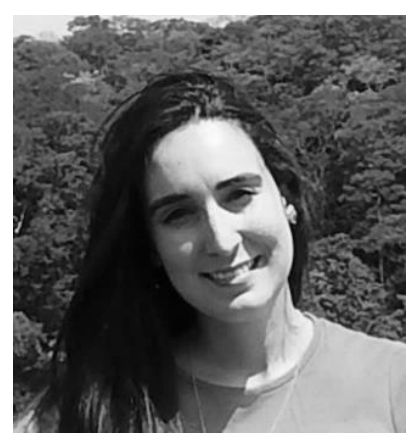

Andeise Cerqueira Dutra nasceu na Bahia. Recebeu o BSc em Engenharia Florestal pela Universidade Federal do Recôncavo da Bahia (UFRB) em 2017 e o MSc em Sensoriamento Remoto pelo Instituto Nacional de Pesquisas Espaciais (INPE) em 2019. Atualmente é bolsista do Conselho Nacional de Desenvolvimento Científico e Tecnológico (CNPq) no projeto Sistema de Risco de Incêndio do Bioma Cerrado (SIRI). Seus interesses de pesquisa são fenologia das espécies, mudanças de uso e cobertura da terra, e monitoramento da vegetação em diferentes biomas no Brasil utilizando técnicas de sensoriamento remoto e sistema de informações geográficas. 

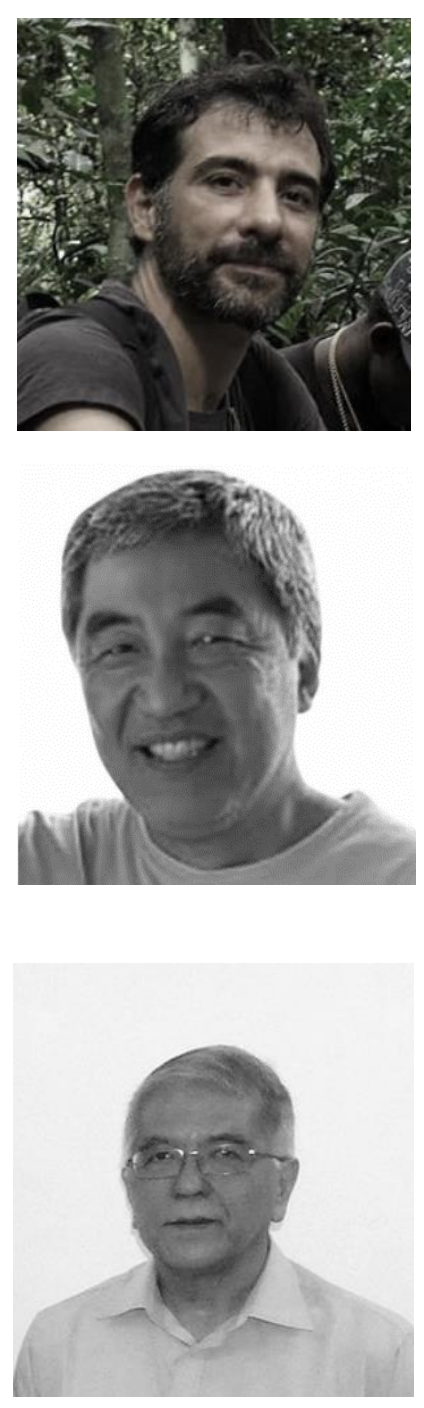

Juan Doblas é engenheiro geofísico, espanhol de nascença. Possui mestrado em Geofísica pelo ENSPM (França) e especialização em SIG pela universidade de Pennsylvania (EUA). Sua atuação profissional tem focado no monitoramento da integridade territorial de Áreas Protegidas na Amazônia e Cerrado brasileiros. Atualmente realiza estudos de doutorado em sensoriamento remoto no INPE, onde tem desenvolvido metodologias de detecção automática de desmatamento utilizando dados SAR.

Egidio Arai recebeu o curso de Tecnólogo em Processamento de Dados pela Universidade de Taubaté (UNITAU), Taubaté, em 1986, MSc em Computação Aplicada, em 2002, e Doutorado em Sensoriamento Remoto, em 2011, pelo Instituto Nacional de Pesquisas Espaciais (INPE), São José dos Campos, Brasil. Atualmente é Tecnologista Sênior no INPE. Seus interesses são ciência da computação e sensoriamento remoto, atuando nos seguintes assuntos: processamento de imagens, séries temporais de imagens, ecossistemas tropicais e ciências ambientais, recursos florestais e sistemas de computador.

Yosio Edemir Shimabukuro recebeu o BSc em Engenharia Florestal pela Universidade Federal Rural do Rio de Janeiro (UFRRJ) em 1972; MSc em Sensoriamento Remoto pelo Instituto Nacional de Pesquisas Espaciais (INPE) em 1977; e PhD pela Colorado State University, EUA em 1987. De janeiro/1992 a março/1994, foi pesquisador visitante no Goddard Space Flight Center da NASA, EUA. Desde 1973, está no INPE, utilizando dados de sensoriamento remoto por satélite e terrestre para análise de cobertura vegetal. Vem aplicando técnicas e modelos de sistema de informação geográfica e sensoriamento remoto para detecção de mudanças ambientais em diferentes biomas do Brasil. É pesquisador 1A do Conselho Nacional de Desenvolvimento Científico e Tecnológico CNPq. 